School funding reform: an empirical analysis of options for a national funding formula

IFS Briefing Note BN123

Haroon Chowdry Luke Sibieta 


\title{
School funding reform: an empirical analysis of options for a national funding formula
}

\author{
Haroon Chowdry and Luke Sibieta*
}

November 2011

\section{Executive summary}

- Schools in England currently receive the bulk of their funding via local authorities, which each have their own funding formula. These formulae can be myriad and complex: different local authorities take into account different factors and fund particular types of schools differently.

- School funding exhibits wide variation. Last year, most primary schools received between $£ 3,000$ and $£ 6,000$ per pupil, while most secondary schools received between $£ 4,000$ and $£ 7,000$. This variation arises largely because schools differ in their characteristics, but funding levels also vary across schools with similar characteristics.

- In 2010-11, we find that primary schools received, on average, an implicit premium of about $£ 2,000$ extra for poorer pupils (defined as those eligible for free school meals). In secondary schools, the premium was roughly $£ 3,400$ extra. This system is 'progressive' in that schools with poorer pupils are funded more generously. While the progressivity has increased over time, schools' finances also depend on historical factors, such as funding in previous years. Funding can thus adjust slowly to changes in pupil needs.

- In the 2010 Spending Review, the government announced a cash-terms freeze in all existing funding per pupil and the creation of a pupil premium targeted at disadvantaged pupils. The net result is to make the school funding system more 'progressive', with the most deprived schools expected to see real-terms increases in funding. However, the majority of schools are expected to see real-terms cuts in funding.

- The government currently intends to make significant reforms to the school funding system in England over the next few years. The main

\footnotetext{
* The authors are grateful to the Esmée Fairbairn Foundation for funding this work (grant number 11/0357) and to the Economic and Social Research Council for providing support through the Centre for the Microeconomic Analysis of Public Policy (grant number RES-544-28-0001). The authors would like to thank Carl Emmerson, Paul Johnson and members of the advisory group for their comments and thoughts, and Judith Payne for copy-editing. Any views expressed are those of the authors only, and any errors and omissions are their responsibility.
} 
proposal is to replace the current system with a simpler one where each school's funding is calculated centrally according to a single national formula, with only some discretion for local authorities to vary funding around these levels. This would make the funding of schools more transparent and more consistent across the country. We analyse different options for a national funding formula, and how they would affect the finances of different schools and areas of the country. Such analysis was not present in the Department for Education's most recent consultation on school funding reform. This Briefing Note therefore provides the only in-depth analysis of the implications of the proposed reforms to school funding.

- The first key finding from this analysis is that the funding formula must be designed extremely carefully: features currently proposed by the government could lead to a redistribution of funding from secondary to primary schools. This can easily be prevented by adjusting the ratio of secondary to primary school funding. It is also important to recognise that current deprivation funding (measured by the implicit premium for free school meals) is geared strongly towards secondary schools.

- Changes in funding will be concentrated in particular local authorities; some could see average gains or losses of $10 \%$ or more. In some cases, the changes amongst primary and secondary schools are offsetting, reflecting greater harmonisation across local authorities in the ratio of secondary to primary school funding. In other cases, both primary and secondary schools are expected to see large changes in funding. If one believes that a single national funding formula represents an appropriate system of school funding, then such local authorities would be deemed to be currently over- or under-funded. Alternatively, one might believe that such local authorities have higher or lower levels of educational need than those implied by the factors upon which a national formula might be based.

- The third key finding is that, whatever formula is chosen, it will lead to a large number of winners and losers relative to existing policy. This is an inevitable consequence of replacing the current system, where funding levels can be based on myriad historical and local factors, by a simpler version that seeks to make funding more transparent and consistent across the country.

- We consider the likely time period required to smooth the transition to a national funding formula. Any transition period of less than a decade will involve significant, sustained losses for some schools. For example, in a transition lasting six years, some schools would incur annual cashterms funding losses of up to $5 \%$. 
- The crucial question for the government is whether the advantages of a national formula - simplicity, transparency and responsiveness of funding - exceed the costs that the adjustment process would entail. However, maintaining the status quo is unlikely to be desirable either. Without reform, school funding may become less transparent and less related to educational needs over time. The fact that there will be winners and losers per se is not necessarily an argument against reform. If one believes that a national funding formula represents the most desirable system, then the numbers of winners and losers merely show how far the status quo is from an ideal scenario. Moreover, failing to implement substantial reforms to school funding would lead to a further drift away from the desirable system and a greater cost of implementing reform towards it in future.

\section{Introduction}

This year, the government has completed two consultations on school funding reform in England. ${ }^{1}$ The first set out the overall principles that should guide reform of school funding, emphasising the need for a simpler and fairer system. The second consultation made specific proposals and sought views on how a national funding formula for schools should be designed. The government is yet to publish its response to this second consultation.

In this Briefing Note, we describe the options for a national funding formula for schools and examine how different options would affect the finances of different schools or areas of the country. Our analysis is based on data held by the Department for Education (DfE). Curiously, such analysis was not present in DfE's second, more detailed, consultation on school funding reform. The lack of such analysis makes serious public debate difficult. This report therefore provides the only in-depth analysis of the implications of the proposed reforms to school funding. In presenting this analysis, our goal is to ensure that policy development and public debate are based on detailed and rigorous empirical evidence.

Under the current system, schools receive the bulk of their funding via local authorities, which each set their own funding formula. These

\footnotetext{
${ }^{1}$ Department for Education (2011), A Consultation on School Funding Reform: Rationale and Principles (http://www.education.gov.uk/consultations/downloadableDocs/School\%20Funding\% 20Reform\%20consultation\%20final.pdf).

Department for Education (2011), A Consultation on School Funding Reform: Proposals for a Fairer System (http://www.education.gov.uk/consultations/downloadableDocs/July\%2011\%20Consu Itation\%20on\%20School\%20Funding\%20Reform\%20FINAL.pdf).
} 
formulae can be myriad and complex. Different local authorities may take into account different factors, while some may fund particular types of schools more generously than others do. The result is that schools with similar characteristics, located in different areas, can have different levels of funding. Local authorities also fund schools on the basis of historical factors, which serves to dampen the relationship between a school's present circumstances and its present level of funding.

The government's main proposal is to replace this system with a simpler one where each school's funding would be calculated centrally according to a single national formula, with only some discretion for local authorities to vary funding around these levels. This would make the funding of schools more transparent and more consistent across the country. Such a reform would represent the single largest change to the school funding system since the introduction of the local management of schools in 1991.

Imposing a single formula across the country can clearly create winners and losers: some schools would see an increase in funding while others would see a reduction. The government would also be choosing to implement this reform alongside real-terms cuts to the overall schools budget, limiting its ability to compensate the losers or ease the transition to the new system.

The fact that there will be winners and losers is not necessarily an argument in itself against reform. If one believes that a national funding formula represents the most desirable school funding system, then the numbers of winners and losers merely show how far the status quo is from the ideal scenario. Moreover, failing to implement substantial reforms to school funding would lead to a further drift away from the desirable system and a greater cost of implementing reform towards it in future.

Our analysis illustrates the financial implications of different options for a national funding formula, allowing us to consider the size of such changes and which options are likely to minimise the numbers of winners and losers. We show which schools and areas are likely to be most affected, to help policymakers and the public consider whether these changes are desirable and feasible. Furthermore, we are able to consider explicitly the potential transition process to such a funding formula.

This Briefing Note proceeds as follows. Section 2 describes the current funding system and the strength of the relationship between how much funding schools receive and their characteristics (such as the proportion of pupils from a disadvantaged background). It also documents how responsive school funding allocations are to changes in needs over time. Section 3 elaborates on the options one must consider when designing a national funding formula and discusses the merits of these different 
options. Section 4 contains the detailed empirical analysis, which models several potential examples of a national funding formula and examines how many schools might gain or lose, as well as the magnitudes of these effects. Section 5 then considers the transitional issues if such a system were to be implemented, examining the time frame required given the scale of potential disruption to school finances that a national formula might create. Section 6 concludes and draws together the key messages of this research.

\section{The current school funding system}

In this section, we describe the key features of the current school funding system in England and how it has evolved in recent years. Currently, there are two main types of state-funded schools in England - maintained schools and academies - which are funded in different ways. We begin by describing the way maintained schools are funded and then how academies are funded, before briefly discussing free schools. We describe empirically how 'progressive' the distribution of school funding is - that is, whether schools with poorer pupils receive more funding per pupil - and examine how the progressivity has changed over time. Finally, we assess the implications of previously announced changes to school funding over the coming years.

\subsection{Maintained schools}

Maintained schools receive the vast majority of their funding from local authorities, though local authorities do not raise the majority of this money themselves. Each year, local authorities receive an allocation from the Dedicated Schools Grant. Over recent years, this has been calculated based on the so-called 'spend-plus' methodology. Under this method, local authority grants have been determined as a flat-rate increase on what schools or local authorities received in the previous year, plus an extra increase determined on the basis of a formula. The retrospective aspect of this methodology limits the ability of the school funding system to redistribute money between local authorities on the basis of changing need. Although the Dedicated Schools Grant was introduced in 2006, the 'spend-plus' methodology was brought in following the school funding 'crisis' of 2003-04, when a number of schools complained that they were due to receive cuts in funding. Before then, grants to local authorities were based on a known formula that sought to measure the needs of different local authorities, though these formulae often had mechanisms aimed at ensuring stability in funding levels as well.

Local authorities' allocations from the Dedicated Schools Grant are 'ringfenced', meaning that they must be spent on pupil provision in support of a local authority's schools budget. Local authorities are free to add to this 
money using other sources, such as other grants that are not ring-fenced, council tax revenues and local charges for some council services. However, only $10 \%$ of local authorities actually do so.

Some of this schools budget is spent on central services provided by the local authority, such as high-cost special educational needs and school admissions. This amount varies by local authority. On average, local authorities retain about $13 \%$ of their schools budget for central services, while $10 \%$ of local authorities retain less than $9 \%$ and $10 \%$ retain more than $17 \%$ of their schools budget.

Each local authority then has its own 'fair-funding' formula for allocating the remainder of its schools budget to schools. This is intended to ensure that schools within a local authority that have similar characteristics (in terms of the pupils they serve) receive the same level of per-pupil funding. The formulae vary by local authority, but the most important element of them is clearly pupil numbers. Overall, the most common aspects of these fair-funding formulae are:

- the number of pupils at each Key Stage;

- indicators of social deprivation, such as the number of pupils eligible for free school meals (FSM);

- Individually Assigned Resources for pupils with a statement of special educational needs (SEN);

- number of pupils with SEN without a statement;

- number of pupils with English as an additional language (EAL);

- site and school factors (the school's business rates bill, an amount per square metre of the school's site, and many other factors).

In recent years, local authorities have been constrained in how they set their formulae by a number of factors. Rules such as the Central Expenditure Limit have restricted the growth in spending on central services. Meanwhile, the Minimum Funding Guarantee (MFG) guarantees each school a minimum increase in funding per pupil each year. It limits the impact of local authorities' fair-funding formulae, as the formula allocations are ignored if the annual increase in funding they imply is less than the level of the MFG. When it was introduced, the MFG was originally set at a relatively high level: in 2004-05, it was $4 \%$ per pupil in cash terms, constituting two-thirds of the overall cash increase in the Dedicated Schools Grant (6\%). However, its impact has slightly reduced over time: in 2010-11, it accounted for half of the increase in the Dedicated Schools Grant. The proportion of schools receiving top-up payments as a result of 
the MFG has also fallen from around 30\% of schools in 2004-05 to about $25 \%$ in $2010-11.2$

The combination of the 'spend-plus' methodology and the MFG seems likely to have weakened the relationship between school funding levels and measures of educational need over time. The 'spend-plus' methodology means that local authorities' total resources will have been less well targeted than could otherwise have been the case, and the MFG will have weakened the ability of an individual local authority's funding formula to redistribute funding between schools with changing needs. This is an issue to which we return later in this section.

The amount provided via fair-funding formulae is the largest single source of each individual school's funding. However, over the past decade, schools have increasingly received funding from another source: specific grants calculated and distributed by central government. Local authorities have no say over how these are allocated. Instead, they must pass the grants on in full directly into schools' bank accounts. Examples of specific grants include the School Standards Grant, School Development Grant and other standards funds.

The operation of the school funding system, combined with differences in pupil characteristics across schools, creates a wide range of funding per pupil across schools in England. Figure 2.1 plots the distribution of perpupil funding in 2010-11 for (a) primary schools and (b) secondary schools, expressed in 2010-11 prices. It also plots the distributions for 2006-07 (dashed lines) in order to show how they have changed over time. The vertical solid lines indicate the average (mean) level of funding in 2010-11, while the dashed vertical lines show the average level of funding in 2006-07.

Both distributions exhibit a wide amount of dispersion, with 2010-11 primary funding per pupil tending to vary between around $£ 3,000$ and $£ 6,000$ (with an average of $€ 4,080$ ), while 2010-11 secondary funding per pupil tends to vary between about $£ 4,000$ and $£ 7,000$ (with an average of $£ 5,320) .^{3}$ A small number of schools exhibit funding levels outside these regions. The distributions for 2010-11 lie to the right of the corresponding distribution for 2006-07, indicating that there was a general increase in real-terms funding per pupil over this period.

\footnotetext{
${ }^{2}$ Dispensation can be given to derogate from the Minimum Funding Guarantee with the permission of the local authority Schools Forum and/or the Secretary of State. This applied to around $22 \%$ of schools in 2010-11.

${ }^{3}$ The median primary funding per pupil is $£ 3,840$, while the median secondary funding per pupil is $₫ 4,760$.
} 
Figure 2.1. Empirical distribution of funding per pupil in 2006-07 and 2010-11

a) Primary schools

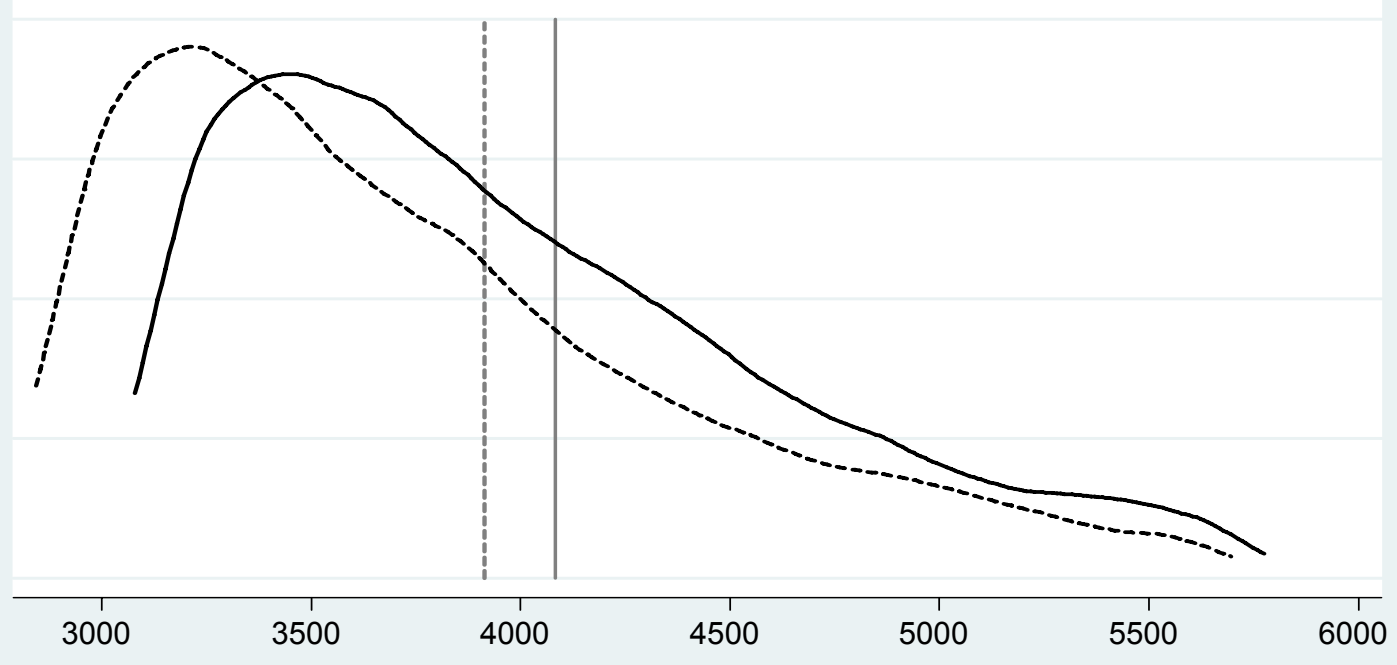

Funding per pupil (£, 2010-11 prices)

\section{b) Secondary schools}

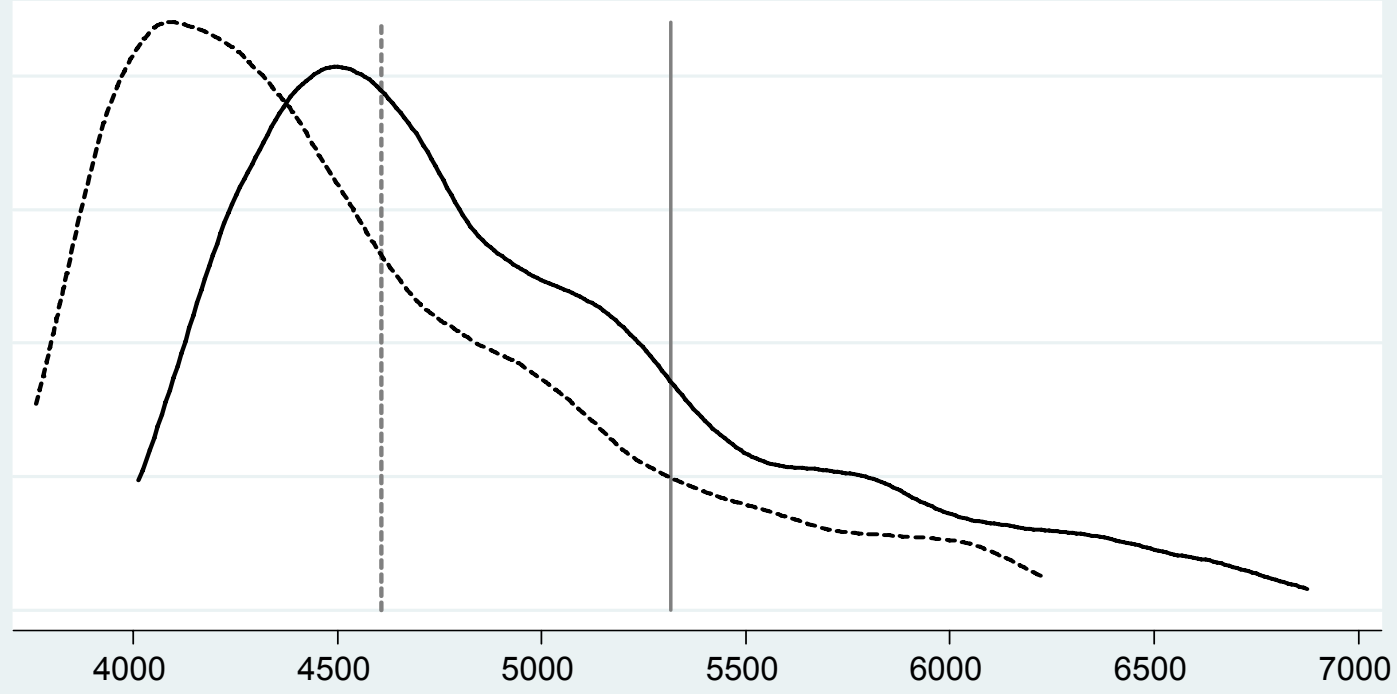

Funding per pupil (£, 2010-11 prices)

Notes: Estimated amounts are in 2010-11 prices using the GDP deflator. The vertical lines indicate the mean level of funding in the relevant year.

Sources: School financial data are based on Section 251 Budget Data. GDP deflators are from Office for Budget Responsibility, Economic and Fiscal Outlook, March 2011 (http://budgetresponsibility.independent.gov.uk/economicand-fiscal-outlook-march-2011/). 
In previous work, ${ }^{4}$ we analysed which pupil characteristics (implicitly) explain the largest proportions of schools' funding. We have repeated this exercise here, using statistical techniques to isolate the impact of various school-level characteristics on their overall level of funding. Here, we highlight some of the key conclusions from this analysis (see Appendix Tables A.1 and A.2 for the full results). We focus on funding for pre-16 education, thereby excluding funding for sixth forms from the Learning and Skills Council.

When examining all funding for primary and secondary schools, we see that it is highly skewed towards schools with greater numbers of pupils with SEN (particularly if they have a statement ${ }^{5}$ ) and towards schools with greater numbers of pupils from deprived backgrounds. On average, there was an implicit FSM premium of about $£ 2,000$ for primary schools and $£ 3,400$ for secondary schools in 2010-11. This would be on top of the basic amounts provided for all pupils, meaning that we estimate that in 2010-11 primary schools receive 83\% extra funding for each pupil eligible

Figure 2.2. Implicit FSM premium over time

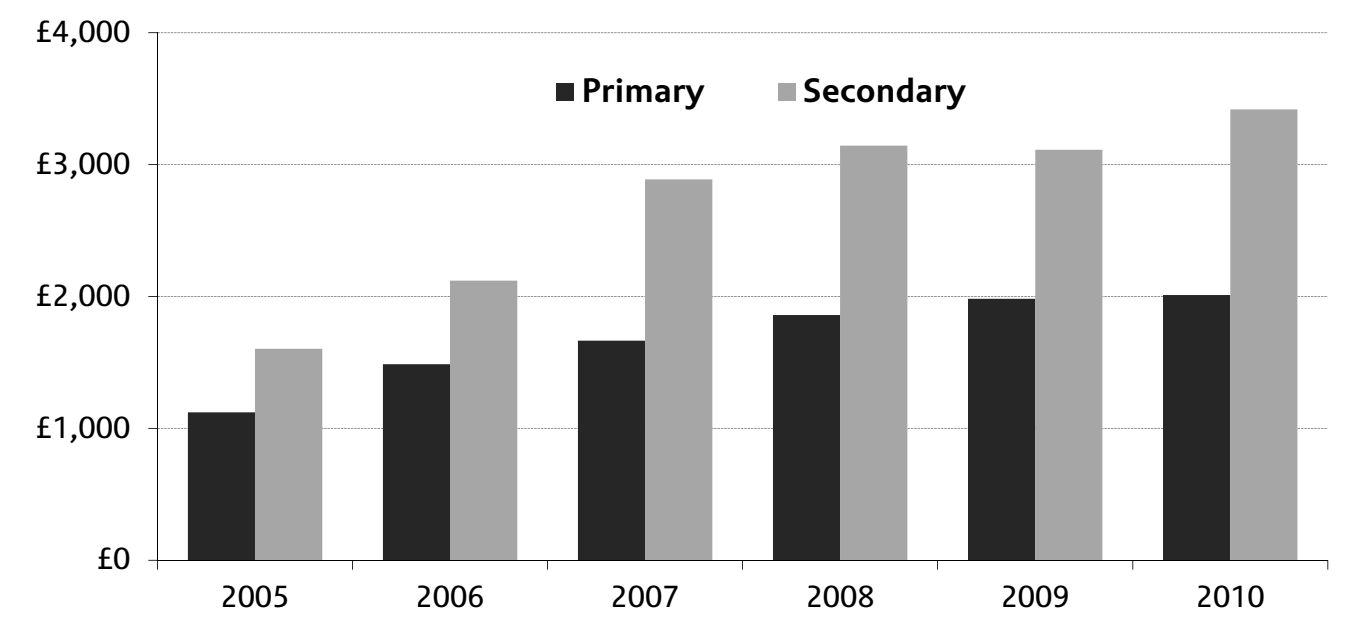

Notes: Estimated amounts are in 2010-11 prices using the GDP deflator. Years are academic years, e.g. 2005 means 2005-06.

Sources: School financial data are based on Section 251 Budget Data. GDP deflators are from Office for Budget Responsibility, Economic and Fiscal Outlook, March 2011 (http://budgetresponsibility.independent.gov.uk/economicand-fiscal-outlook-march-2011/).

\footnotetext{
${ }^{4} \mathrm{H}$. Chowdry, A. Muriel and L. Sibieta (2008), Level Playing Field? The Implications of School Funding, Research Paper, Reading: CfBT Education Trust (http://www.ifs.org.uk/publications/4252).

H. Chowdry, E. Greaves and L. Sibieta (2010), The Pupil Premium: Assessing the Options, Commentary 113, London: Institute for Fiscal Studies (http://www.ifs.org.uk/publications/4776).

${ }^{5}$ A statement of special educational needs is coordinated between the local authority, parents and the school. The statement sets out the level of provision needed for the pupil, and consequently determines how much extra funding they require.
} 
for FSM compared with a pupil who is not, and secondary schools receive an extra $96 \%$ of funding per pupil eligible for FSM.

As Figure 2.2 makes clear, these implicit FSM premiums have grown substantially since $2005-06$, from $£ 1,100$ to $£ 2,000$ in primary schools and from $£ 1,600$ to $£ 3,400$ in secondary schools (all in 2010-11 prices), doubling in real terms in just five years. This is far in excess of overall growth in funding per pupil over this period; school funding has certainly become more targeted at more deprived schools over recent years.

Figure 2.3 confirms that the implicit basic amount per pupil has grown by far less than the implicit FSM premium over the past five years. It also separates out the contribution to these basic amounts from local authorities' fair-funding formulae and from central government specific grants. It shows that specific grants from central government contribute significantly more to the implicit FSM premium than to the implicit basic amount provided for all pupils. Specific grants have driven much of the growth in the implicit FSM premium in recent years, though fair-funding formulae have also become more targeted at deprived schools. Overall, the use of specific grants has made the school funding system more progressive in recent years.

In previous analysis, ${ }^{6}$ we have shown that local authorities' funding formulae are less targeted at deprivation than the allocations they receive from the Dedicated Schools Grant. In other words, local authorities seem to spread or 'flatten' the funding they receive for deprived pupils, distributing it across all the pupils in the area. Specific grants from central government may have been devised in response to such flattening. However, it is clear from Figure 2.3 that the estimated implicit FSM premium in local authority funding formulae has grown faster than the estimated implicit basic amount. This means the degree of flattening has fallen over time.

The above analysis only shows the average amount of funding associated with particular school characteristics in any given year, which masks two key points. First, in reality there is likely to be variation around these averages as different local authorities prioritise different factors. Second, the analysis so far does not show the degree to which changes in funding over time are associated with changes in a school's characteristics, i.e. how responsive school funding is to any change in the needs of the school. We now seek to address both of these issues.

\footnotetext{
${ }^{6}$ H. Chowdry, E. Greaves and L. Sibieta (2010), The Pupil Premium: Assessing the Options, Commentary 113, London: Institute for Fiscal Studies (http://www.ifs.org.uk/publications/4776).
} 
Figure 2.3. Implicit basic amount and FSM premium over time, by source

a) Primary schools

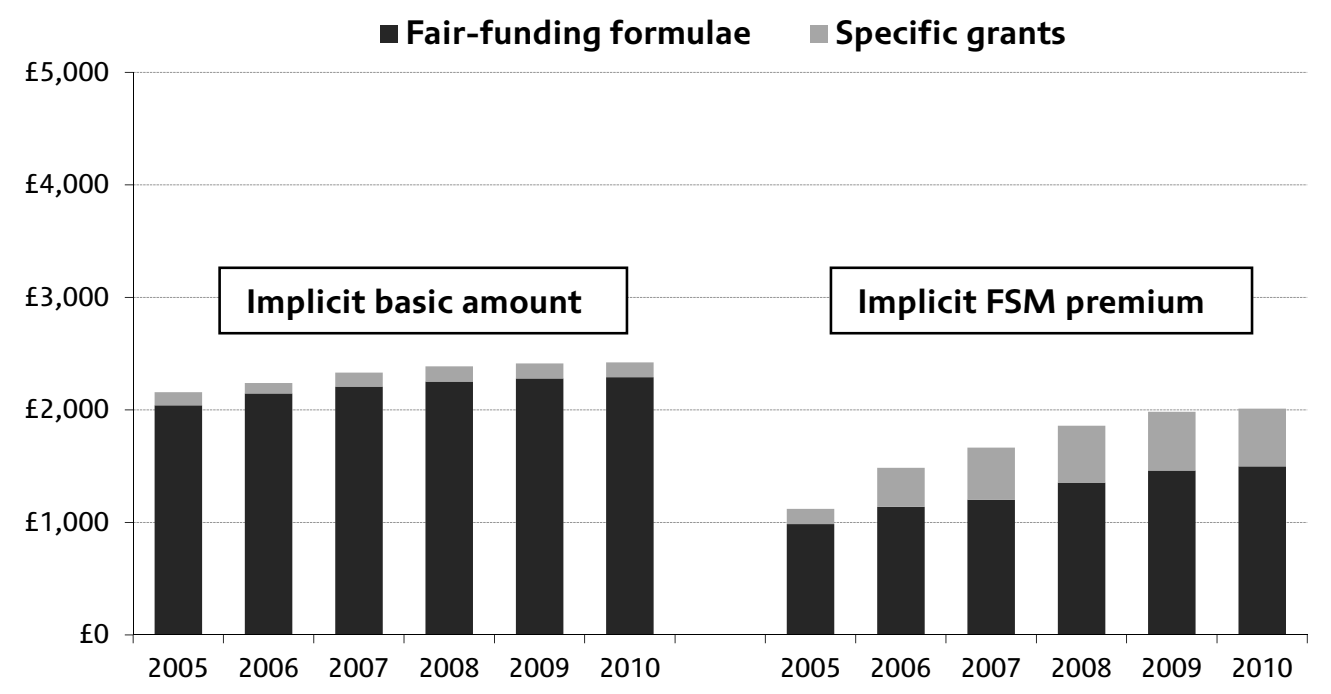

b) Secondary schools

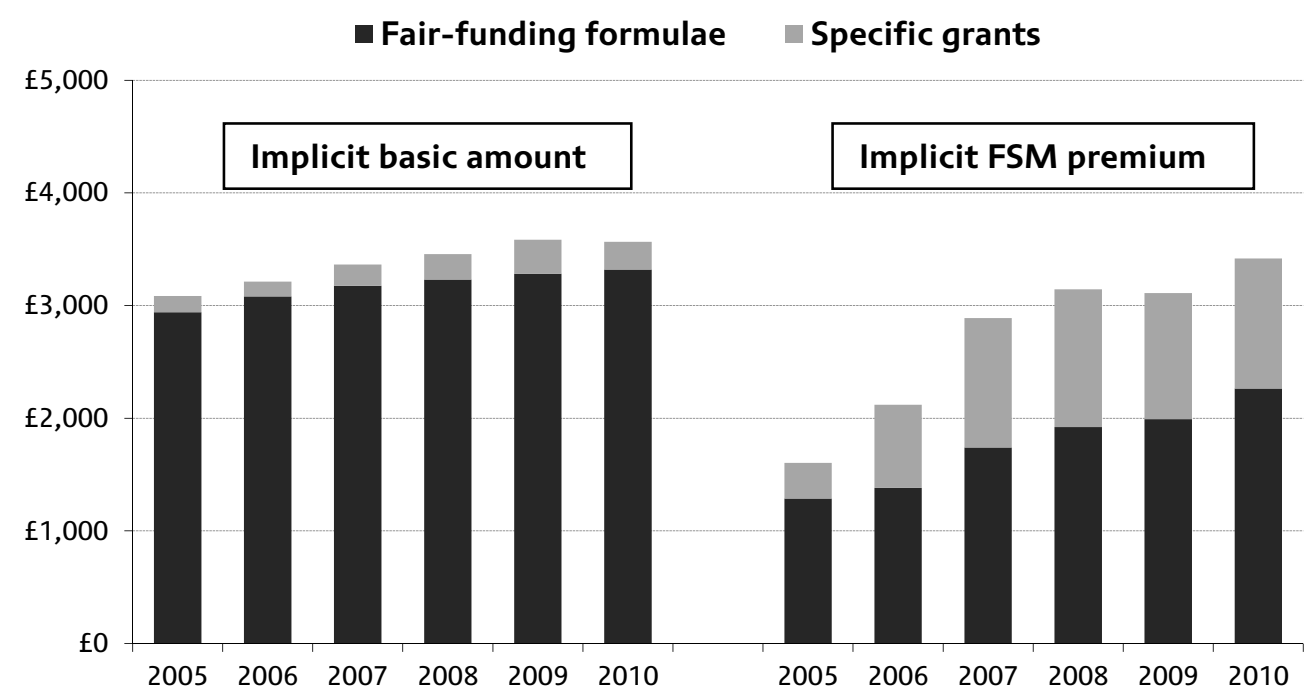

Notes: Estimated amounts are in 2010-11 prices using the GDP deflator. Years are academic years, e.g. 2005 means 2005-06.

Sources: School financial data are based on Section 251 Budget Data. School-level characteristics are taken from LEASIS (Local Education Authority and School Information Service). GDP deflators are from Office for Budget Responsibility, Economic and Fiscal Outlook, March 2011 (http://budgetresponsibility.independent.gov.uk/economic-and-fiscaloutlook-march-2011/).

Figure 2.4 shows the percentage difference between schools' actual funding levels and what they would be predicted to receive based on their observable characteristics (including the characteristics of their pupils). This is shown separately for (a) primary schools and (b) secondary schools. Each graph shows how this pattern has changed between 200506 (grey line) and 2010-11 (black line). 
Figure 2.4. Percentage difference between schools' actual and predicted funding a) Primary schools

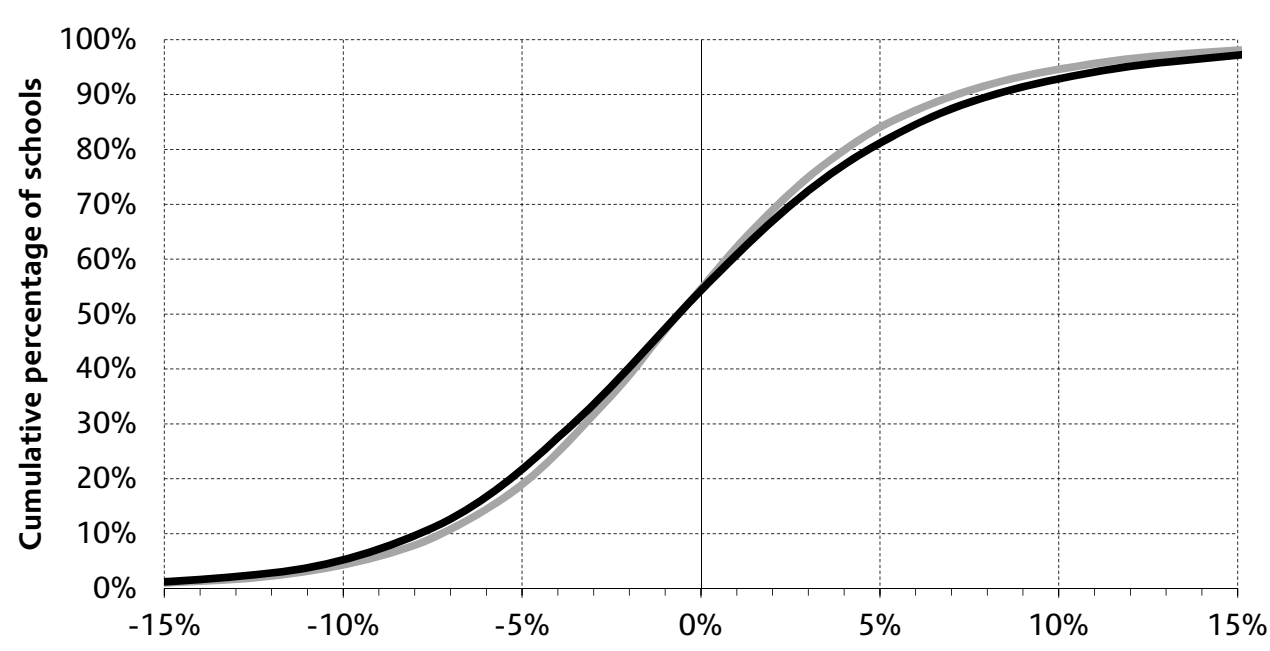

Percentage difference between actual and predicted funding levels

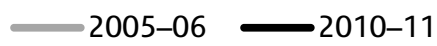

b) Secondary schools

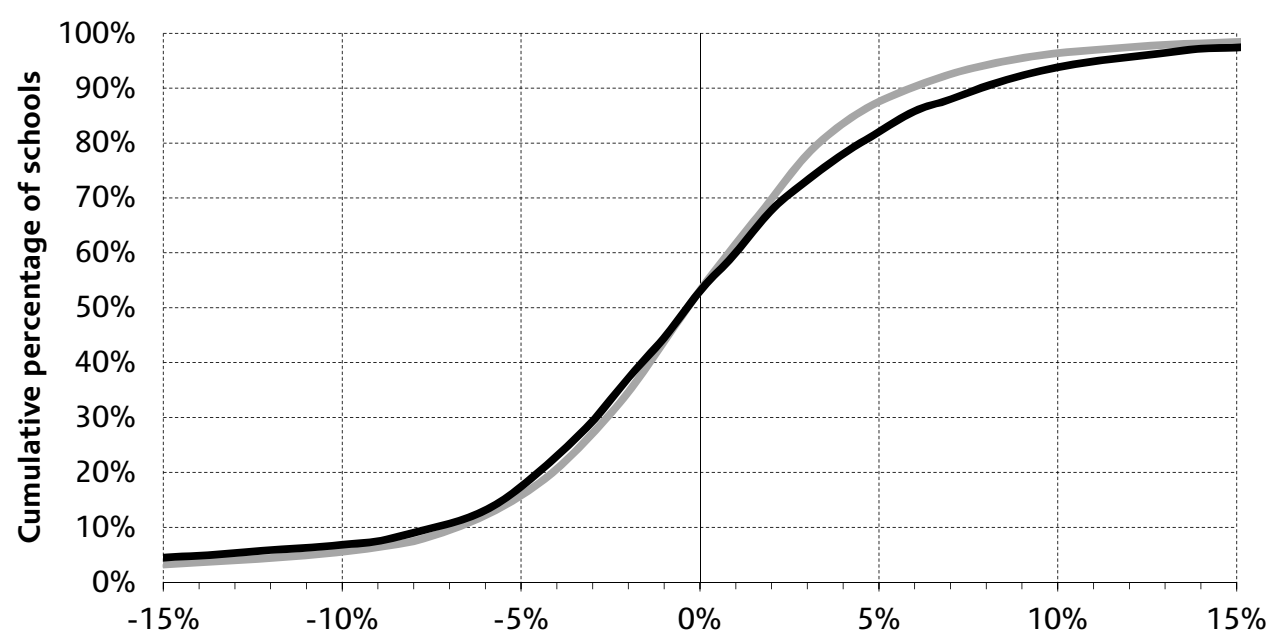

Percentage difference between actual and predicted funding levels

-2005-06 $2010-11$

Note: Estimated amounts are in 2010-11 prices using the GDP deflator.

Sources: School financial data are based on Section 251 Budget Data. School-level characteristics are taken from LEASIS (Local Education Authority and School Information Service). GDP deflators are from Office for Budget Responsibility, Economic and Fiscal Outlook, March 2011 (http://budgetresponsibility.independent.gov.uk/economic-and-fiscaloutlook-march-2011/).

In $2010-11,7 \%$ of secondary schools had funding at least $10 \%$ lower than would be predicted based on their observable characteristics, while $6 \%$ had funding at least $10 \%$ higher than would be predicted. Hence $87 \%$ of secondary schools in 2010-11 had a level of funding within $10 \%$ of what would be predicted; this compares with around $91 \%$ of secondary schools 
in 2005-06. About 65\% of secondary schools in 2010-11 had funding levels within $5 \%$ of what would be predicted based on their observable characteristics, compared with $72 \%$ in $2005-06$. Primary schools exhibit a similar pattern.

In other words, schools in similar circumstances can have quite different funding levels. As we might expect, given the operation of the 'spend-plus' methodology and the Minimum Funding Guarantee, these differences have grown since 2005-06. However, they were significant even then. This situation could lead to a number of policy conclusions.

First, one could conclude that this shows just how far the status quo is from a simple, national funding formula, and confirms the need for reform if a single national formula is believed to be ideal. Since these differences have grown over time, this interpretation would suggest that the case for reform has also grown over time. Alternatively, one could conclude that the current level of these differences simply reflects the different choices currently made by local authorities. However, at least some of the increase in these differences over time will reflect the MFG and the 'spend-plus' methodology. Thus some schools' and local authorities' funding levels will have drifted away from their appropriate level and so there is still a need to reform the allocation of funding to local authorities at the very least. The implications for reform thus depend on the degree to which one believes that existing differences across similar schools reflect local discretion or unnecessary inequality. But either interpretation would suggest a need to reform the school funding system.

A school's level of funding may be strongly related to the characteristics of its pupils at a point in time, but, as mentioned above, there are also important retrospective factors at play. Therefore it does not necessarily follow that school funding levels respond quickly to changes in need; funding can instead be slow to adjust.

To see how responsive the current system is to changes in need, Figure 2.5 plots the estimated implicit premiums that result when the change in a school's funding level is related to the change in its characteristics from one year to the next. The grey bars show the implicit basic amount and implicit FSM premium, for both primary and secondary schools, based on the change between 2009-10 and 2010-11 (expressed in 2010-11 prices). ${ }^{7}$ For the purposes of comparison, the black bars show the implicit basic amount and implicit FSM premium when looking at the relationship between current school funding (in 2010-11) and current school

\footnotetext{
${ }^{7}$ See Appendix Tables A.3 and A.4 for the full set of estimated amounts.
} 
characteristics. The black FSM premium bars therefore use the same figures as those for the implicit FSM premium (for 2010-11) in Figure 2.2.

Figure 2.5 demonstrates that the relationship between changes in funding and changes in need is systematically weaker than the relationship between the level of funding and the level of need. Secondary schools currently get an implicit basic amount of just over $£ 3,500$ per pupil, but if a school's intake rises by one pupil from one year to the next, it will only receive an extra $£ 1,650$. Secondary schools with poorer pupils receive a significant implicit premium for pupils with FSM $(£ 3,400)$, but if the degree of deprivation rises at a particular school, the resulting increase in funding will only be around two-thirds of this. In other words, while schools with more pupils or more deprived pupils have considerably more funding than other schools, if the same schools experienced an increase in the number of such pupils from one year to the next, their funding would only increase by a small amount.

Figure 2.5. Responsiveness of school funding to changes in pupil numbers or deprivation

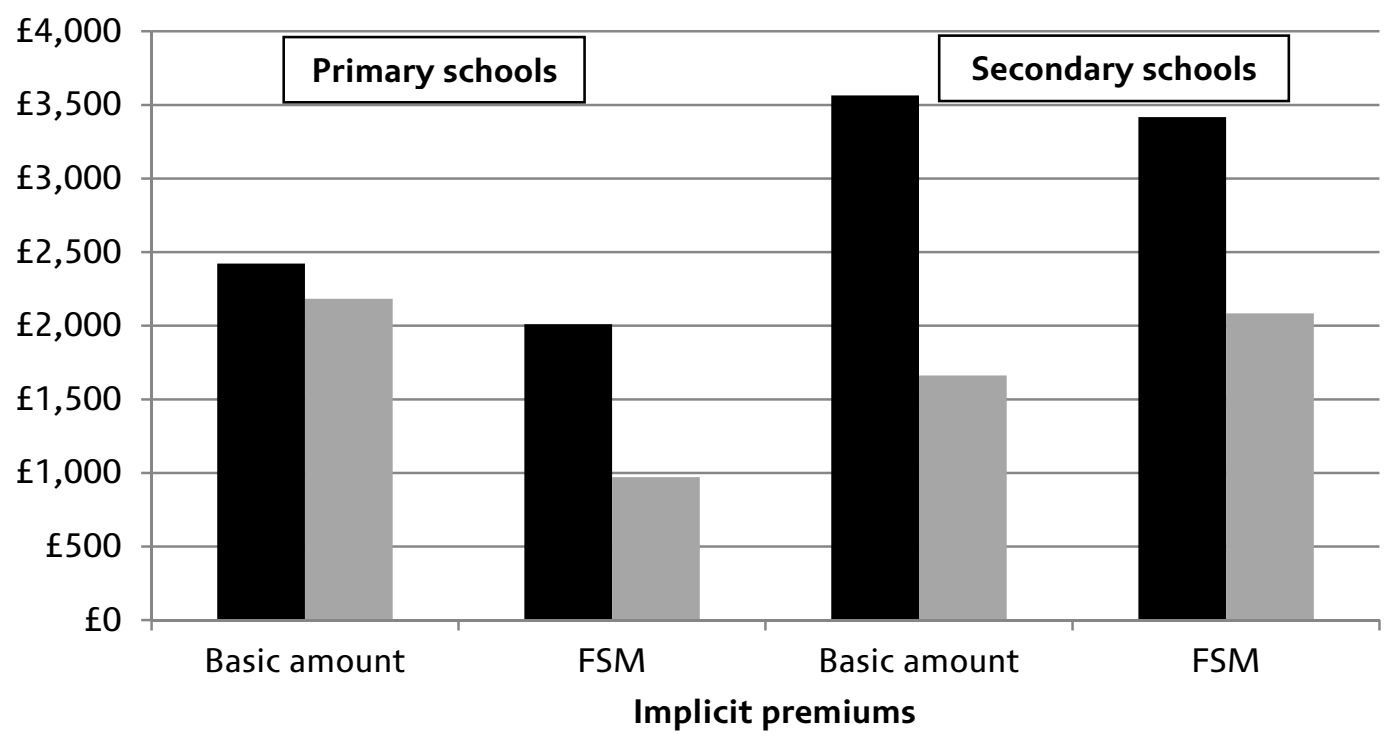

- Level per pupil in 2010-11 —Change per extra pupil from 2009-10 to 2010-11

Note: Estimated amounts are in 2010-11 prices using the GDP deflator.

Sources: School financial data are based on Section 251 Budget Data. School-level characteristics are taken from LEASIS (Local Education Authority and School Information Service). GDP deflators are from Office for Budget Responsibility, Economic and Fiscal Outlook, March 2011 (http://budgetresponsibility.independent.gov.uk/economic-and-fiscaloutlook-march-2011/).

In principle, a national funding formula would remove this disparity by replacing the historical aspects of school allocations with an explicit, concrete link between their current circumstances and their current level of funding. However, doing so could also introduce some volatility in school funding levels as a school's characteristics evolve over time. There is an inherent trade-off between the responsiveness and the stability of 
school funding levels. In Section 5, we revisit the issue of potential volatility in school funding levels when considering the transition to a national funding formula.

\subsection{Academies}

Academies operate outside of local authority control and are funded directly by the DfE via the Young People's Learning Agency (YPLA). The YPLA provides a grant to all academies known as the General Annual Grant. ${ }^{8}$ The intention is that academies should receive the same funding as maintained schools with similar pupils in the same local authority.

Although this sounds like a simple principle, the mechanics are considerably more complex. First, the YPLA does not know the precise formulae used by local authorities to distribute money to schools, and has previously attempted to replicate these formulae based on published information. As the government acknowledged in the consultation on academies' funding published earlier this year, ${ }^{9}$ 'There is a risk of error during the replication process [and] ... the process becomes more difficult with an increasing number of Academies'. In the immediate term, the government thus plans to roll forward current per-pupil funding in academies. This circumvents the difficulty of having to replicate local authority fair-funding formulae. However, if continued indefinitely, it would create a financial incentive for academies to admit fewer disadvantaged pupils over time and would provide fewer extra resources to academies that became more deprived over time as compared with maintained schools. An exception to this is the new pupil premium, which will be paid on top of current funding. However, it is considerably smaller than the implicit amount targeted at deprived pupils in existing funding.

The second complication is that, being independent of local authorities, academies no longer benefit from the provision of central services by the local authority. Instead, academies also receive funding to cover the cost of providing these services themselves. This income is known as the Local Authority Central Spend Equivalent Grant (LACSEG). It is calculated by taking the average amount spent per pupil by the local authority on central services and is allocated to academies on a per-pupil basis. Overall, therefore, academies receive higher levels of funding than similar maintained schools in the same local authority, but in return have

\footnotetext{
${ }^{8}$ Academies are also provided with grants to cover VAT, insurance, rates and other costs not encountered by maintained schools.

${ }^{9}$ Department for Education (2011), Academies' Pre-16 Funding: Options for the 2012/13 Academic Year

(http://www.education.gov.uk/consultations/downloadableDocs/Academies\%20Fundi ng\%20Consultation\%20Document.pdf).
} 
responsibility for the provision of more services. The LACSEG only provides academies with a net increase in their effective resources if they are able to provide the required services more efficiently than the local authority does, or if their usage of central services was below average for the local authority. Conversely, if academies are less capable of providing these services efficiently (perhaps due to an inability to exploit economies of scale) then they would have less effective resources than similar maintained schools.

\subsection{Free schools}

In addition to expanding the number of academies over time, the government has also enabled the creation of free schools, inspired by the popularity of such schools in Sweden. Free schools are set up and managed by parents and other non-state providers, and need to demonstrate local demand before they are approved by central government. They are also independent of central and local government. Twenty-four free schools opened in September 2011, with more planned for September 2012 and beyond.

Like academies, free schools receive their funding directly from central government. Until recently, the funding has mainly covered start-up and pre-opening costs. As of September 2011, free schools also receive revenue funding to cover teacher salaries and other day-to-day costs. The formula used to allocate such funding to free schools aims to provide the same level of funding to free schools as is provided to similar maintained schools in the same local area, in a simple and transparent manner. Each free school receives funding on the following basis:

- a fixed sum of $£ 95,000$ for each primary or all-through school;

- a basic local funding unit for each pupil attending the school;

- a local funding unit for each pupil eligible for FSM;

- an additional national pupil premium for each pupil eligible for FSM;

- a LACSEG and SEN grant (like academies, free schools are responsible for services previously provided by the local authority);

- separately calculated funding for sixth-form pupils;

- a grant to cover the cost of insurance and rates.

The basic local funding unit and the local funding unit for FSM pupils are calculated based on estimates of the current balance of funding between primary and secondary schools implied by local authority funding formulae, and the current level of funding targeted at deprivation by local authorities, respectively. The size of the LACSEG and SEN grant is determined on the same basis as for academies. Since the formula for free school funding differs across local authorities, free schools with similar characteristics that are located in different local authorities may receive 
different levels of funding. This is the result of existing differences in local authority funding formulae and the Department's desire that free schools be funded on a similar basis to other state-funded schools in the same local authority.

It is not currently possible to analyse free schools' funding levels as they have only recently opened and the required information does not exist. However, in Section 4.4, we will analyse the implications of using the free school funding formula to determine funding for maintained schools. This will allow us to judge whether the free school funding formula is more or less generous - and if so, for which types of school - than the current funding formula for maintained schools.

\subsection{Changes to school funding in 2011-12 and by 2014-15}

The government has made a number of changes to the way in which school funding is provided in 2011-12, and has further plans for changes over the following three years. The main changes introduced in 2011-12 are the streamlining of specific grants provided to schools and the introduction of a pupil premium. In the 2010 Spending Review, 10 the government announced that existing spending per pupil (the Dedicated Schools Grant plus streamlined specific grants) would be frozen in cash terms in 201112.

The pupil premium will provide schools with a fixed extra amount of money for each deprived or otherwise disadvantaged pupil. This will add to the already considerable amount of funding attached to deprived pupils (about $£ 3,400$ at secondary schools and $£ 2,000$ at primary schools). A pupil premium could: (i) simplify the current system; (ii) weight funding even more towards disadvantaged pupils; and (iii) make school funding levels respond more quickly as the make-up of schools' student bodies changes. In the long run, the government has stated that the pupil premium should become the primary mechanism for distributing all deprivation funding to schools and would therefore replace all current deprivation funding.

In 2011-12, the pupil premium is set at $£ 488$ for each pupil eligible for free school meals, $£ 488$ for each child in care and $£ 200$ for children in service families. ${ }^{11}$ In total, it is expected to cost $£ 625$ million in 2011-12.

\footnotetext{
${ }^{10}$ See http://www.hm-treasury.gov.uk/spend index.htm.

${ }^{11}$ http://www.education.gov.uk/inthenews/inthenews/a00199131/schools-to-geteven-more-pupil-premium-cash-this-year.
} 
In previous work, ${ }^{12}$ we have analysed the implications of these policy decisions for the budgets of schools across England in 2011-12. We showed that whether one considers economy-wide inflation or an estimate of schools-specific cost inflation, the majority of primary and secondary schools are expected to see real-terms cuts in per-pupil funding in 201112 ; only the most deprived ones would expect to see a real-terms increase.

The pupil premium will be gradually expanded over time, with a total budget of $£ 2.5$ billion available in $2014-15$ as set out in the 2010 Spending Review. This would equate to $€ 1,900$ for each pupil eligible for FSM in 2014-15 (leaving £110 million for an expanded pupil premium for children in care or in service families). In our previous work, we also estimated changes in funding per pupil across schools in 2014-15; Figure 2.6 reproduces this analysis. ${ }^{13}$ It shows the percentages of primary and secondary schools expected to see cash-terms funding increases between 2010-11 and 2014-15 of a given value or less, assuming that existing perpupil funding is frozen in cash terms and that the pupil premium is

Figure 2.6. Change in school funding levels in cash terms in 2014-15

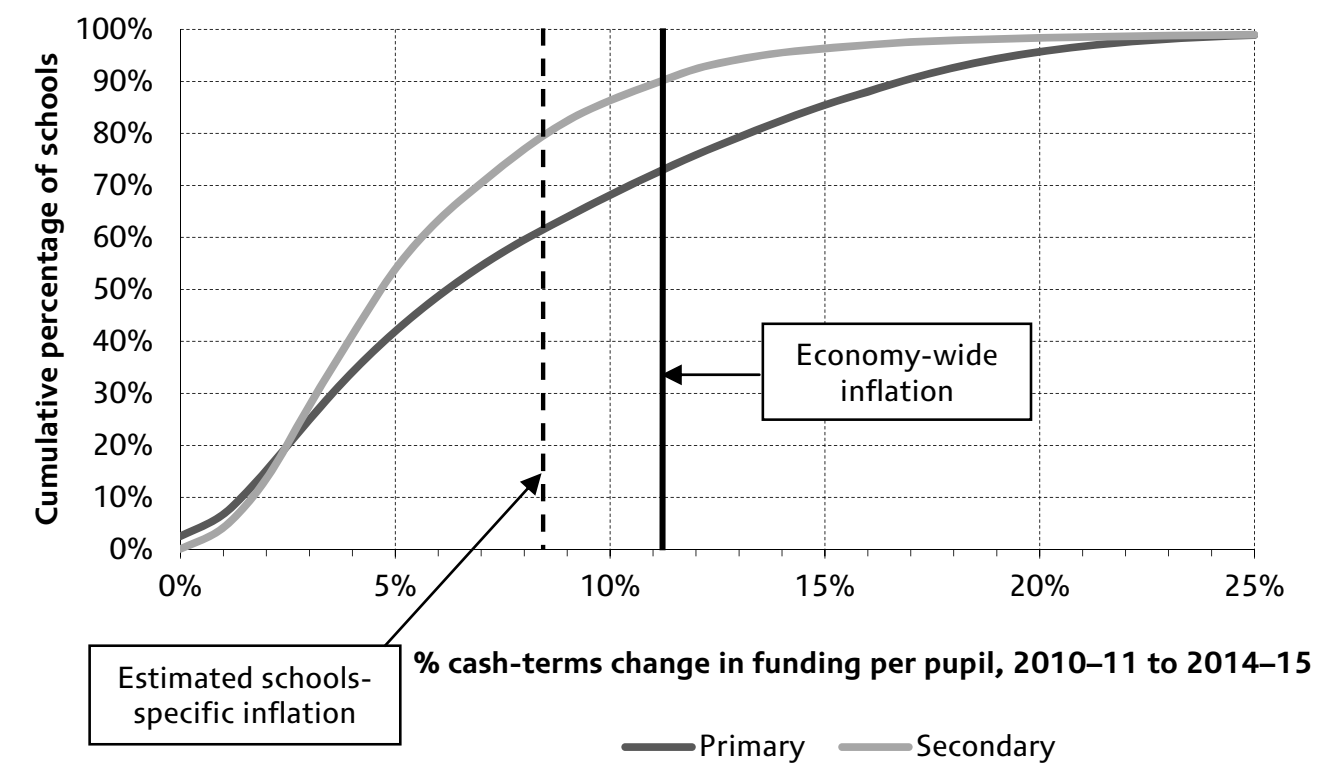

Sources: School financial data are based on Section 251 Budget Data. School-level characteristics are taken from LEASIS (Local Education Authority and School Information Service) and National Pupil Database. GDP deflators are from Office for Budget Responsibility, Economic and Fiscal Outlook, March 2011

(http://budgetresponsibility.independent.gov.uk/economic-and-fiscal-outlook-march-2011/).

\footnotetext{
${ }^{12}$ H. Chowdry and L. Sibieta (2011), Trends in Education and Schools Spending, Briefing Note 121, London: Institute for Fiscal Studies (http://www.ifs.org.uk/publications/5732).

${ }^{13}$ It should be noted that Figure 2.6 uses more up-to-date data than those used in Chowdry and Sibieta (2011) - referenced in footnote 12 . The specific numbers thus differ very slightly, but the overall pattern is largely unchanged.
} 
increased to $£ 1,900$ by 2014-15. It also shows the expected rate of cumulative economy-wide inflation over this period $(11.2 \%$, shown by the vertical black line) and an estimate of cumulative schools-specific cost inflation ( $8.4 \%$, shown by the dashed line).

The graph shows that nearly three-quarters of primary schools would see an increase in funding below economy-wide inflation between 2010-11 and $2014-15$, as would $90 \%$ of secondary schools. Around two-thirds of primary schools and $80 \%$ of secondary schools would see real-terms cuts, measured against our estimate of schools-specific inflation. About half of primary schools are likely to receive cash-terms increases at least 5 percentage points below economy-wide inflation, as are over $60 \%$ of secondary schools. As a result of the pupil premium, about 3\% of secondary schools will see increases at least 5 percentage points higher than inflation, as will over $10 \%$ of primary schools.

\subsection{Conclusion}

While the level of funding schools receive has increased in recent years, it exhibits very wide variation. To a large extent, this is because schools differ in their characteristics: those with a larger proportion of disadvantaged or high-needs pupils tend to be funded more generously. However, there is still considerable variation in funding levels across schools with similar characteristics, because (i) different local authorities use different fair-funding formulae and (ii) funding reforms such as the Minimum Funding Guarantee have led to the budgets in some schools diverging from what might be expected based on the school's observable characteristics. This variation in funding levels across schools with similar characteristics has grown since 2005.

While we do not know the actual formulae that determine how much funding schools receive, it is clear that two of the largest determinants of funding are the headcount of pupils and the number of disadvantaged pupils. We find that primary schools tend to receive, on average, a premium for pupils eligible for FSM of about $£ 2,000$ more than for a noneligible pupil. In secondary schools, the premium is roughly $£ 3,400$. These implicit premiums have grown in recent years, making the allocation of school funding increasingly progressive. However, school finances also depend on historical factors, such as funding received in previous years. An explicit, transparent formula would ensure that funding levels respond immediately to changes in need.

These conclusions suggest that the school funding system is in need of reform. However, the nature of this reform depends on what the ideal school funding system looks like in principle. If one believes that a single national funding formula represents an ideal system, then there was a strong case for reform in 2005 and this case has grown stronger over time. 
If, on the other hand, one believes that local authorities should have the freedom to prioritise different factors, then there is simply a need to rebase local authority allocations on more recent measures of educational need.

By introducing a pupil premium targeted at the most disadvantaged children, the government has made the school funding system even more progressive from 2011-12. However, due to a cash freeze in other perpupil funding, only the most deprived schools will see real-terms increases in funding per pupil. The majority are expected to see real-terms cuts in 2011-12. This will also be true in 2014-15, despite the planned expansion of the pupil premium.

\section{Designing a national funding formula for schools}

In this section, we discuss options for the design of a national funding formula, paying particular attention to the proposals set out in the most recent consultation on school funding. We begin by discussing the overall structure of a national funding formula, before discussing the potential content of the formula (for example, number of pupils, measure of deprivation and other factors).

\subsection{Overall structure of national funding formula}

There are many different ways to structure a national funding formula. The simplest possible one would involve a fixed monetary amount for all pupils, potentially different for primary and secondary schools. This would essentially be a pure voucher system (except that schools would not be able to charge top-up fees). As a slight modification, one could choose to allocate extra funding for pupils from disadvantaged backgrounds. This could reduce any disincentives to attract such pupils by providing additional resources to schools with large numbers of disadvantaged pupils. This is one of the motivations behind the pupil premium.

A further modification could be to allow for non-pupil-led factors. For instance, schools in high-cost areas might need to pay more to attract teachers and could thus be funded at a higher level. Further considerations could include whether to provide additional support to small schools via lump-sum amounts.

In principle, a national funding formula could take into account many different pupil-led and non-pupil-led factors. Crucially, however, it would be set by central government and the funding would be allocated directly to schools according to this formula; the allocation would no longer be determined by local authorities. The separate formulae used by local authorities would be replaced by a single one, representing a very substantial reform to the school funding system. 
An alternative structure involves using a formula to determine funding levels for local authorities and leaving local authorities to set their own formula to pass the funding on to schools. This is not a true national funding formula. Instead, it would represent a return to the early 2000s, when local authorities were funded on the basis of a known formula but chose how to allocate funding to schools in their area.

The relative merits of these two structures depend on whether one feels that local or central government has a better idea of educational needs across schools, and the extent to which one is prepared to accept differences in funding across similar schools in different areas. Their merits will also depend on the desired structure of the overall schooling system. A 'true' single national funding formula would be better suited to a market-based system with many independent providers, whereas the second structure would be suited to a model that envisages a substantial role for local authorities. However, in the short run, one must also consider the costs of moving to a new funding system: replacing all local authorities' fair-funding formulae with a single formula is likely to involve substantial numbers of winners and losers. This is an issue to which we return in Section 4.

In its most recent consultation on school funding, the government proposed two options for a national funding formula somewhere in between the two structures discussed above. In its first option, the government would calculate the allocations for individual schools based on the characteristics of the pupils, schools and the local area. In particular, the new formula would include:

- a basic amount per pupil;

- additional funding for deprivation;

- additional funding to protect small schools;

- an adjustment for areas with higher labour costs.

Local authorities would receive the total allocation across all maintained schools in their area. They could pass this on to schools, or deviate at their discretion by prioritising certain factors in their own formula or using different factors. However, the degree to which local authorities could deviate from the school-level allocations in the central government formula would be restricted (see below for further details).

The government's second option involves a national formula for allocating funds to local authorities (rather than schools), which would then be responsible for choosing how to allocate these funds to the maintained schools in their area. This is very similar to the current system and the second structure discussed above, with the important exception that there 
would be further restrictions on the factors local authorities could use in their formulae.

In either case, the changes would not be in place until at least 2013-14. In 2012-13, a shadow settlement will be published to indicate what school budgets would be had the formula been introduced in 2012-13.

In principle, the two options are identical in terms of how funds are allocated to local authorities. If the government believed that the allocations to local authorities under the first option were optimal, then it is difficult to see why these would not also be optimal under the second option. The key question therefore is whether it is appropriate to publish school-level allocations, as would happen under the first option. It is hard to see why this should not be done if government feels that these represent fair and logical funding levels. Either way, local authorities would have some freedom to deviate from these allocations and would need to justify doing so to their Schools Forum (and, ultimately, local voters).

We now turn to the potential content of the formula restrictions on local authorities. In particular, we discuss:

- the basic amounts provided for all pupils;

- the pupil premium and deprivation funding;

- adjustments for small schools;

- adjustment for labour costs across areas;

- SEN funding;

- spending by local authorities on central services;

- academies and free schools.

\subsection{Basic amount}

The most important element of any national funding formula would be the basic amount allocated for each pupil. In the current system, Age Weighted Pupil Units (AWPUs) determine the basic amounts allocated to schools for pupils falling into different age groups - Key Stage 1 (ages 5-7), Key Stage 3 (ages 11-14) and Key Stage 4 (ages 14-16) - as a multiple of the funding received for pupils at Key Stage 2 (ages 7-11).

Figure 3.1 demonstrates the amount of current variation in these ratios across local authorities (note that the AWPU for Key Stage 2 is 1.0 in every local authority; the other AWPUs are always relative to this). The grey bars indicate the average AWPU level across all local authorities, while the black markers indicate the $10^{\text {th }}$ and $90^{\text {th }}$ percentiles in 2010-11. On average, schools receive $50 \%$ more funding for pupils aged 14-16 than for pupils aged 7-11. At the extreme end of the scale, some schools receive $70 \%$ more funding for such pupils. 
Figure 3.1. Current AWPU ratios, 2010-11

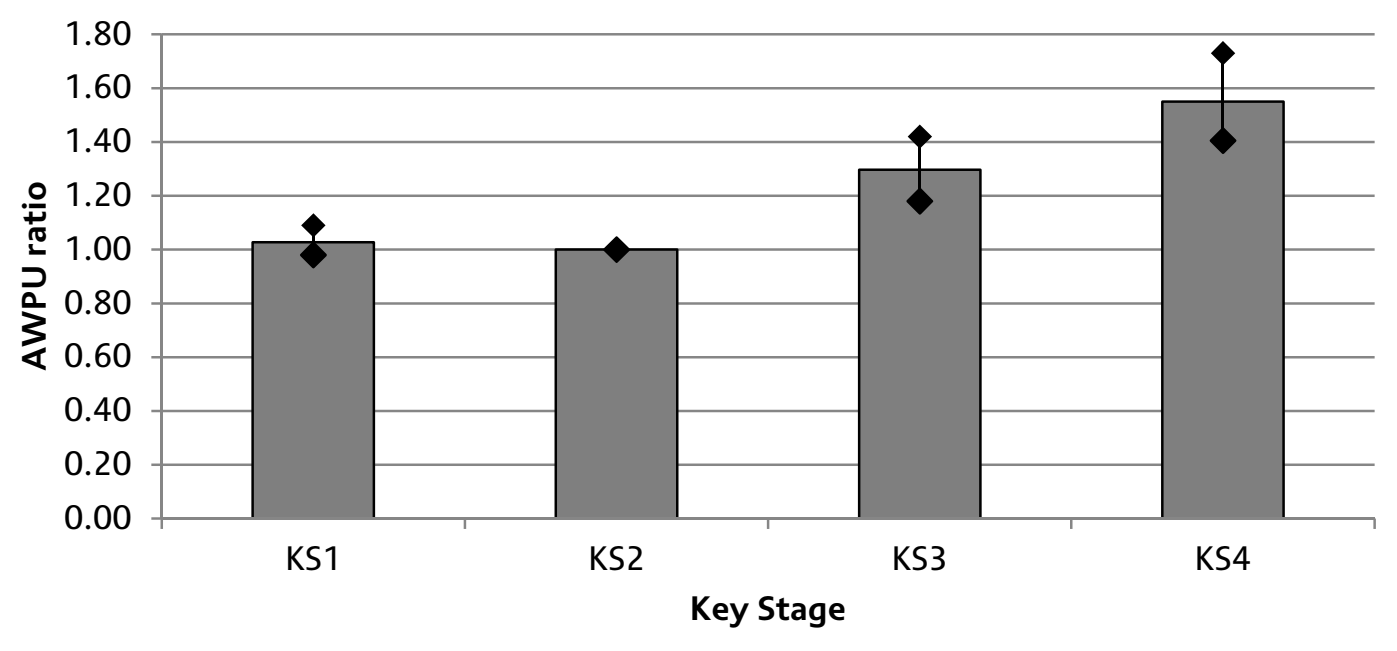

$\square$ Average $\bullet$ 10th and 90th percentiles

Source: Benchmarking tables of LA planned expenditure: 2010-11

(http://www.education.gov.uk/childrenandyoungpeople/strategy/financeandfunding/section251/a0069747/benchmark ing-2010-11).

A national funding formula would need to set monetary values for these AWPU factors. If it is not intended to redistribute funding from secondary to primary schools compared with the current system, then a national funding formula would need to allocate higher amounts of basic funding to secondary schools. However, a government may well wish to alter the distribution of such funding in favour of primary schools on the grounds of early intervention. The main argument in favour of higher funding for secondary schools would be the higher costs associated with secondary teaching - for example, the breadth of subjects and the materials required.

The most recent consultation did not set out a preferred value for AWPU factors. Instead it simply argued that there should be greater harmonisation in total funding per pupil across the country. The government proposed that local authorities should work towards providing $27 \%$ more funding for secondary school pupils than for primary school pupils. However, instead of stipulating 1.27 as an exact target, the consultation proposed a range of permissible ratios around 1.27 , as a compromise. The width of this range has not been determined; there is clearly a trade-off between the degree of harmonisation achieved and the number of local authorities that must alter their relative funding levels.

Figure 3.2 plots the current level of the ratio between secondary and primary school funding for each local authority in England (represented by the vertical grey bars, ordered from highest to lowest). The solid black line marks the ratio that the government believes local authorities should converge towards (1.27). It is very clear from the graph that in a 
Figure 3.2. Ratio of funding between secondary and primary stages, 2010-11

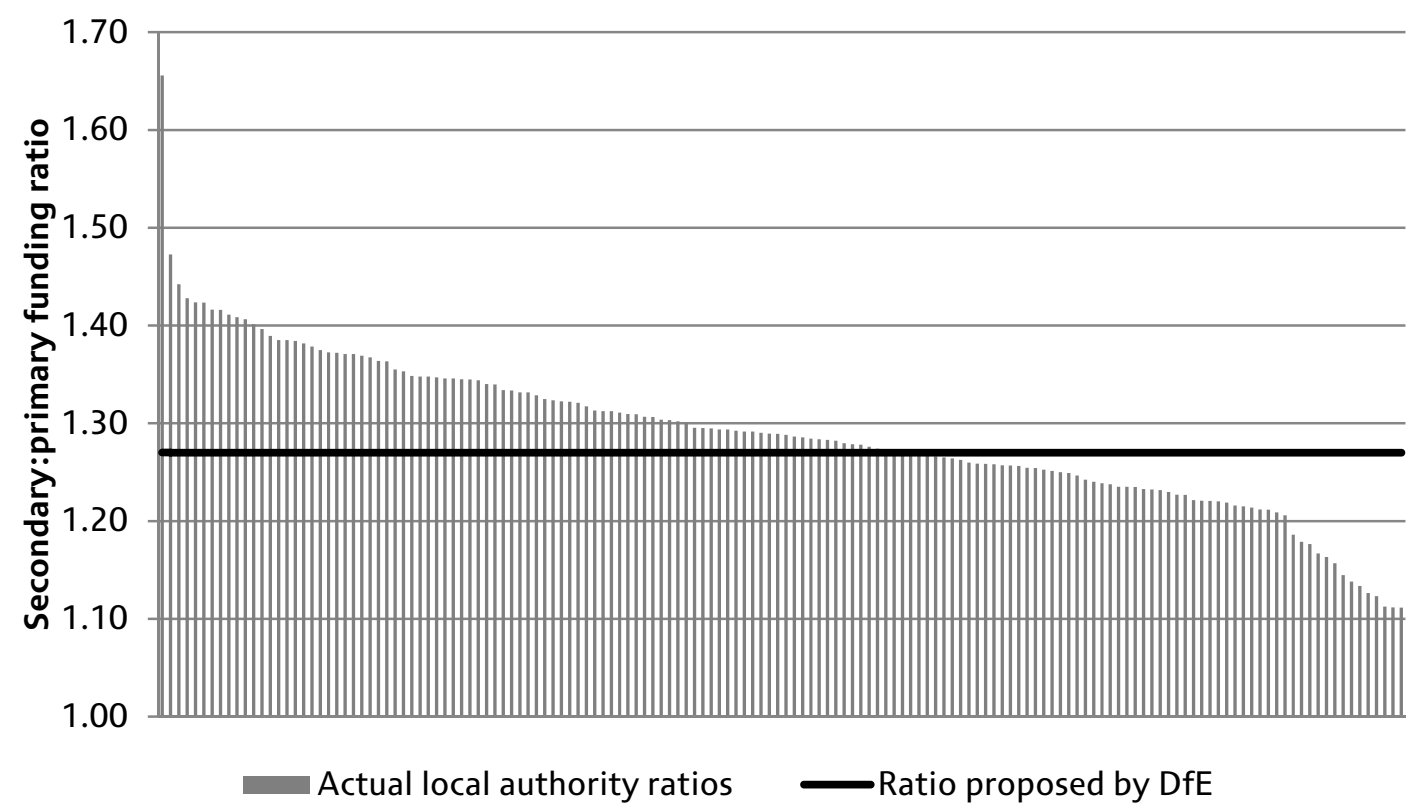

Source: Benchmarking tables of LA planned expenditure: 2010-11

(http://www.education.gov.uk/childrenandyoungpeople/strategy/financeandfunding/section251/a0069747/benchmark ing-2010-11).

significant number of local authorities the ratio differs noticeably from the national average.

To comply with any eventual range of values, local authorities would need to calculate the ratio of total funding per secondary pupil to total funding per primary pupil, adjusting their formulae accordingly if the ratio is outside the allowed range. The consultation did not make clear whether local authorities with a funding ratio outside this range should adjust their AWPUs or some other aspect of funding in order to reach the target range. Either way, the government needs to specify recommended basic amounts or AWPU values (based on some sort of central measure across England) in any school-level funding formula, or the range of allowable ratios between total per-pupil funding at secondary and primary schools.

\subsection{Deprivation funding}

The next key aspect of any national funding formula is deprivation funding. Local authorities have hitherto used a range of deprivation measures in their fair-funding formulae, and in 2011-12 the pupil premium was added to these. In the longer term, the government aims to provide all deprivation funding through the pupil premium, which will make the nominated measure of deprivation extremely important. In the most recent consultation, a number of alternatives were proposed: 
- the number of pupils currently eligible for FSM;

- the number of pupils who have ever been eligible for FSM over the last three or six years;

- an area-based measure of the receipt of means-tested benefits;

- the Income Deprivation Affecting Children Index (IDACI), an area-based measure of the proportion of children in relative poverty.

The primary aim of a pupil premium is to narrow the achievement gap between advantaged and disadvantaged pupils; it should thus be targeted towards groups experiencing disadvantage. Previous IFS research ${ }^{14}$ has considered the merits of different potential measures of deprivation. While it is important to remember that there is no objectively correct answer to the question of which is the ideal indicator, three characteristics of a good deprivation measure can be identified. It should be:

- highly correlated with disadvantage;

- difficult to manipulate by schools or pupils;

- easily observable.

FSM eligibility is the most widely used indicator of disadvantage for school children. In addition, schools should not, in principle, be able to falsely declare pupils as eligible for FSM, as eligibility is based on the receipt of certain means-tested benefits. FSM eligibility is also easily observable in publicly-available administrative data. However, it is a rather blunt measure that cannot identify multiple degrees of deprivation. Also, a disadvantage of the rules determining FSM eligibility is that they lead to schools receiving extra funding for children from poor non-working families but not for children from poor working families.

One issue with the use of current FSM eligibility as a pupil-level deprivation measure is that it will include pupils whose family is temporarily poor, perhaps due to fluctuations in income or employment. The retrospective measures based on FSM that the consultation proposed (whether a pupil has ever been eligible over the last three or six years) would exacerbate this issue, by including children who have been temporarily poor in previous years as well as those who are temporarily poor this year. While it is not clear what the ideal form of FSM eligibility to use is, it is clear that retrospective measures of FSM eligibility are less targeted: they would cover a greater number of pupils and therefore lead to the pupil premium being spread out more thinly. Schools would consequently get less money for pupils in persistent poverty, who might

\footnotetext{
${ }^{14}$ H. Chowdry, E. Greaves and L. Sibieta (2010), The Pupil Premium: Assessing the Options, Commentary 113, London: Institute for Fiscal Studies (http://www.ifs.org.uk/publications/4776).
} 
face greater barriers to learning and achievement. A pupil premium based on retrospective FSM eligibility would also be less progressive than one based on current FSM eligibility (especially for primary schools). It is noteworthy that the consultation did not propose allocating the pupil premium solely on the basis of persistent eligibility for FSM over a number of years. We believe this measure warrants some consideration as it would enable schools to receive more generous financial support for the smaller group of pupils who have experienced severe and persistent deprivation (although schools can always choose to spend this money as they wish).

The two area-based measures of deprivation - means-tested benefit receipt and the IDACI - are correlated with disadvantage (educational and material), are easy to observe and are difficult to falsify. They are also well understood and publicly available. Unlike FSM eligibility, these measures are continuous and can reflect a wide range of levels of disadvantage. They also reflect deprivation as a whole, not just out-of-work deprivation. However, area-based indicators are relatively broad, measuring the circumstances of a pupil's neighbourhood rather than of the pupil themselves. Not every single child living in a deprived area will be disadvantaged, and not every single disadvantaged pupil will live in a deprived area.

A national funding formula could also allocate funding on the basis of the number of pupils who have English as an additional language. It would make sense to include this additional factor if pupils with EAL require more support than non-EAL pupils, even after taking into account disadvantage factors such as FSM eligibility. However, deciding which pupils have EAL is in practice open to some interpretation by schools. The explicit use of an EAL factor in a national funding formula could incentivise the over-reporting of EAL in order for schools to receive extra money.

\subsection{Lump sum for small schools}

The government has also proposed an allowance to help small primary schools with certain fixed costs that do not vary with incremental changes in pupil numbers. In small schools, pupil-led funding may not be sufficient to cover such costs. To alleviate this, the consultation proposed a $£ 95,000$ lump sum for every primary school. The smallest ones would benefit the most because their funding per pupil would increase the most.

It makes sense to give this lump sum to all primary schools rather than only the small ones, to avoid 'cliff edges'. However, the proposal to provide this amount only to primary schools does create an issue. The consultation document argued that secondary schools should not require a fixed lump sum, because the fixed costs that might be an issue (such as school transport) are funded from the local authority Formula Grant. However, the empirical analysis in Section 4 reveals that providing a lump sum only 
for primary schools, combined with the consultation's suggested secondary:primary ratio of 1.27 , would substantially benefit primary schools while penalising secondary schools. The government may have a preference for this outcome, but this was not articulated in the consultation. If such redistribution is not an aim of the reforms, one or both of these elements would have to be revised. We analyse such alternatives in Section 4.

\subsection{Adjustment for local labour costs}

The fourth key element of the national funding formula is an Area Cost Adjustment (ACA) to reflect differences in labour costs across local authorities. This is already present in the funding that local authorities receive, but the government has stated that the ACA has certain weaknesses in its current form and warrants modification.

The current ACA methodology is based on estimates of the differences in wages and salaries across local authorities. These differences are then used as ACA factors. The method is known as the General Labour Market (GLM) approach because the ACA uplift for each local authority is determined by the general level of wages in that area. It is the appropriate uplift to apply if local authorities have to compete with other employers (including the private sector) to recruit staff. If schools were free to set salaries for teaching staff in a competitive manner, then the GLM approach would be the best way of calculating adjustments for labour costs.

However, a national pay structure for teachers exists, which may undermine the assumption upon which the GLM method relies. There is some variation across the country in salaries at each pay grade to reflect regional differences in living costs, but this is not properly aligned with the variation in the ACA, leading to certain anomalies. A handful of Outer London boroughs pay Inner London weighting in teacher salaries while receiving the Outer London ACA (which is less than the Inner London ACA). Schools in such areas are effectively penalised compared with schools in Inner London, which pay the same teacher salaries but receive more generous funding.

One way to reform the ACA would be to base the uplifts on the actual costs of recruiting and employing staff, known as the Specific Costs approach. Unfortunately, while there is good information on the direct costs of employing teachers, there is a lack of reliable data on the indirect costs and on the costs of employing non-teaching staff.

The consultation thus proposed a hybrid approach for calculating the ACA. This would involve the Specific Costs approach to calculate uplift for the direct costs of teaching staff and the GLM approach to calculate uplift for all other costs. The two uplifts would be averaged to create a new 
combined ACA uplift. The consultation published estimates of proposed ACA uplifts under the combined approach and under an updated GLM approach (using the most recent data). Figure 3.3 illustrates the average impact at the regional level of each methodology.

Figure 3.3. Regional impact of changes to ACA methodology

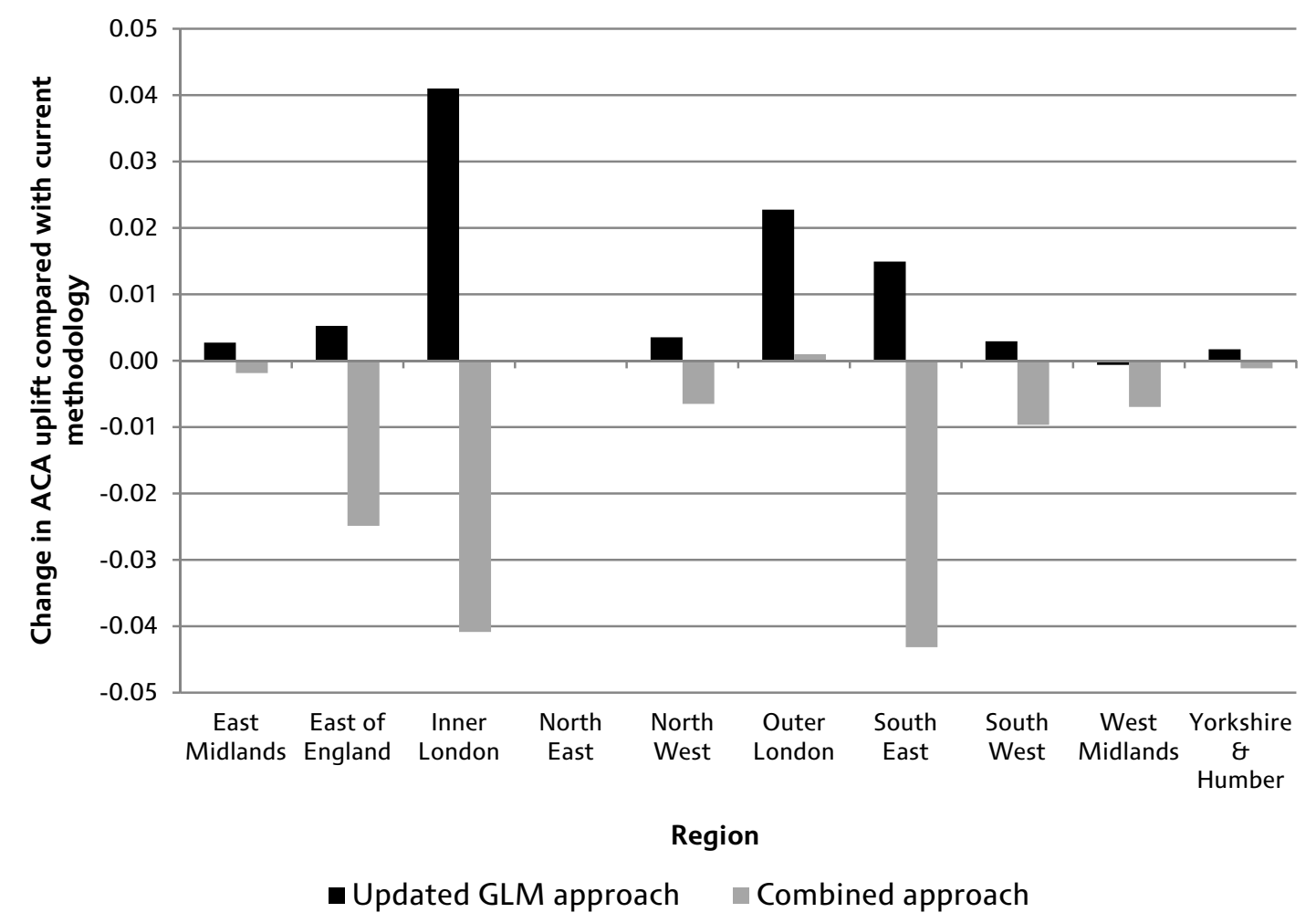

Source: Department for Education (2011), A Consultation on School Funding Reform: Rationale and Principles (http://www.education.gov.uk/consultations/downloadableDocs/School\%20Funding\%20Reform\%20consultation\%20fi nal.pdf).

Local authorities in the North East, along with many in the East Midlands and Yorkshire \& the Humber, would be relatively unaffected by the proposed new ACA factors. The updated GLM approach would increase the generosity with which areas in London and the South East are funded relative to the rest of England. The combined approach, however, would reduce the ACA uplift in the East of England, Inner London and the South East - but not in Outer London, which would benefit very slightly (due to the realignment of its ACA uplift with teacher salary levels). Overall, the updated GLM approach would essentially compound the pattern in the current ACA factors, while the combined approach would reduce the uplifts that well-resourced areas enjoy over the rest of the country.

In a world where schools are bound by a national teacher pay structure, the combined approach appears to be a sensible compromise or 'secondbest', given that schools cannot compete financially for teachers. An alternative justification for the GLM approach, from which areas such as Inner London and the South East benefit considerably, is that schools in 
such areas face the greatest difficulties in attracting and retaining teachers. If true, this would suggest that teachers in such areas are simply underpaid, in which case the situation is best addressed via the teacher pay structure rather than the ACA methodology.

\subsection{High-needs pupils}

Any reforms to school funding would also need to make clear how funding will be provided for pupils with high needs or with special educational needs. Currently, local authorities vary in the way funds are allocated for children with SEN. Under the most common model, some funds are provided to meet the needs of children with low-level SEN, often on the basis of proxy indicators such as the proportion of children eligible for FSM. Beyond that, schools (and parents) must apply to the local authority for additional resources to meet the needs of children with statements of SEN. Such funding is tied to specific provision and resources for individual pupils, and is therefore referred to as Individually Assigned Resources.

Previous research ${ }^{15}$ has demonstrated that the current funding system for children with SEN creates a number of different incentives. First, schools and parents have an aligned incentive to request additional resources from local authorities for pupils with statements of SEN. On the other hand, local authorities have a finite resource and may have an incentive to under-provide for individual pupils. However, when it comes to funds that are delegated to schools for children with SEN, there is potential for disagreement between parents and schools.

In its consultation, the government defined high-needs pupils as those whose total support costs more than $£ 10,000$ annually. Most of these pupils seem likely to have a statement of SEN. The consultation also proposed to provide schools with any additional support for high-needs pupils required above the first $£ 10,000$, which would have to be found from within schools' existing budgets. The extent to which this represents a change to the current school funding system would depend on the extent to which local authorities currently delegate funding for pupils with special educational needs. The effect on individual schools will then depend on the variation in the average level of resources required by highneeds pupils from year to year. If there is a lot of variation, as there may be for some smaller schools, schools may come under significant financial pressure. Unfortunately, the details of local authorities' different funding formulae are not currently published and the level of support required by

\footnotetext{
${ }^{15}$ C. Crawford, L. Sibieta and A. Vignoles (2011), Special Educational Needs Funding Systems: Role of Incentives, Policy Report 11/04, Bristol: Centre for Understanding Behaviour Change (http://www.bristol.ac.uk/cubec/portal/pr4.pdf).
} 
different pupils at individual schools is not known either. It is thus relatively difficult to judge the impact of such reforms.

Another key aspect of funding for high-needs pupils is the formula used to fund special schools and alternative provision (for example, Pupil Referral Units). Most such funding is currently provided on the basis of place-led rather than per-pupil funding. The most recent consultation sought views on the scope to move towards per-pupil funding and proposed ways to avoid 'perverse incentives for local authorities to place high needs pupils in one type of provider rather than another'.16

\subsection{Central services}

Local authorities currently retain a proportion of their schools budget to spend on services that benefit all pupils in the area, and this proportion differs across local authorities as some delegate more responsibilities for providing services to schools. Under the government's proposed school funding reforms, funding for a number of these services would be transferred to schools automatically at the local authority's discretion. In particular, the government proposes the following categorisation of the current set of central services:

- Central Services: services that continue to be provided by local authorities - for example, school admissions and servicing of Schools Forums;

- High-Needs: central services relating to SEN pupils;

- Schools: funding to be transferred to individual schools across all local authorities - for example, repairs of school kitchens;

- Discretionary: funding transferred to schools at the discretion of local authorities and Schools Forums - for example, insurance and the costs of supply staff;

- Early Years: funding for some elements of spending on early years provision, which would be transferred out of the schools budget.

Other education and youth services provided centrally (for example, education psychology or music services) would continue to be funded through the Local Government Settlement.

Figure 3.4 shows how much local authorities spent on these categories of services in 2010-11. In total, around 9\% of the schools budget was spent on them on average, ${ }^{17}$ with considerable variation across local authorities.

\footnotetext{
${ }^{16}$ Page 30 of Department for Education (2011), A Consultation on School Funding Reform: Proposals for a Fairer System.

${ }^{17}$ This figure is lower than that discussed in Section 2, as existing policy already implies that some spending previously counted as central service spending will either be transferred to schools or become part of the early years budget.
} 
The High-Needs category is the largest, accounting for approximately $4 \%$ of the schools budget, on average. Services left to the discretion of local authorities and Schools Forums represent the second-largest element of local authorities' current spending on central services $(2.6 \%$ of the schools budget, on average).

Figure 3.4. Level and variation in local authority spending

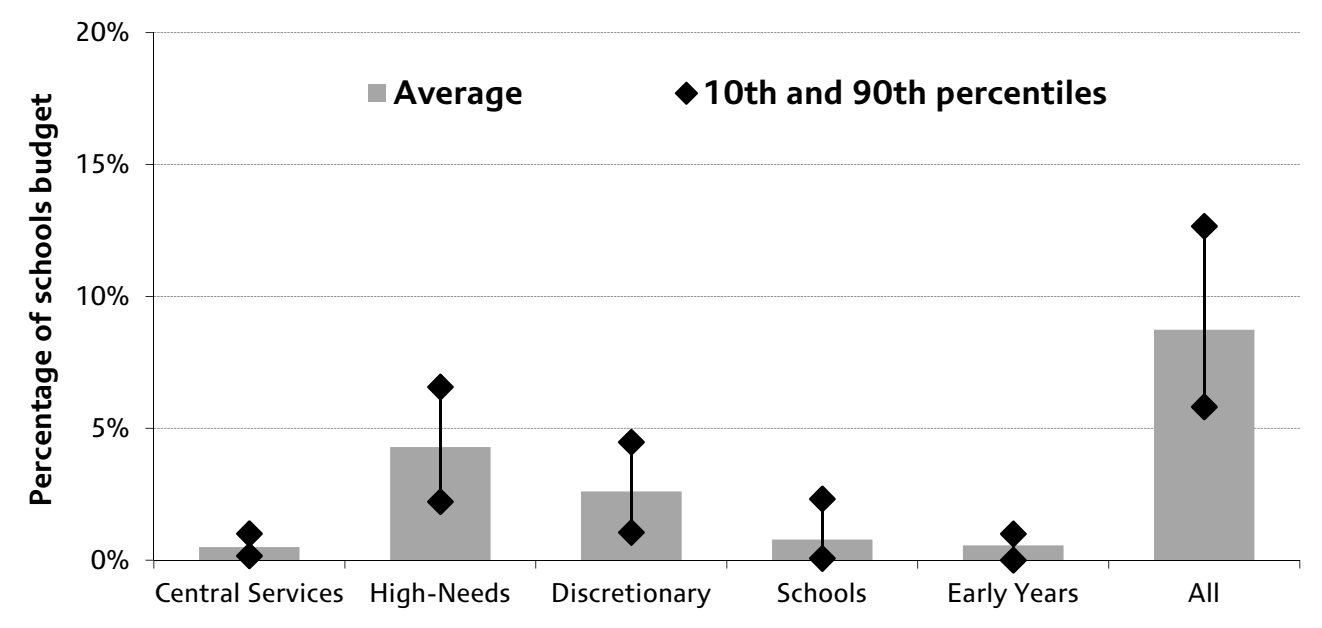

Source: School financial data are based on Section 251 Budget Data, table 1, 2010-11.

Services that will remain centrally provided represent a relatively small proportion of local authorities' schools budgets, at less than $1 \%$ on average, and vary little across local authorities. The level of funding being transferred to schools is relatively modest, also representing less than $1 \%$ of the schools budget, on average.

Given this amount of variation, the proposed reforms to central services represent a relatively modest transfer of spending from local authorities to schools, though it may be considerable for a small number of local authorities. A larger proportion of the schools budget will be transferred to schools only at the discretion of Schools Forums. If all such spending were transferred to schools, then spending by local authorities would be considerably lower and would mainly consist of spending on high-needs pupils.

Going forwards, the government has not explicitly stated how funding for these central services will be distributed across local authorities once the reforms are implemented, merely stating that the total funding will reflect the total resources available and that transitional measures will take account of baseline levels. A number of options for distributing the central services block exist, such as fixed per-pupil amounts or a formula based on the characteristics of pupils, schools and areas (as with the Local Government Settlement). Alternatively, the government could roll forward existing spending levels. We recommend that the government explicitly sets out how it plans to determine the eventual funding levels for central 
services and services transferred at discretion, under the proposed system.

\subsection{Academies and free schools}

The final issue is how academies and free schools should be treated in the new school funding system. The government seeks to fund them on an equivalent basis to other similar schools in the area.

The consultation made a number of proposals for the way academies could be funded in the new school funding system. First, local authorities could calculate how much academies would receive under their own formula and inform the Education Funding Agency, which would then pay this amount to the academies. Second, the Education Funding Agency could replicate the formulae of local authorities based on a pro-forma description of their new, simpler formulae. In principle, these options will have the same implications for academies if no errors are made; the only difference is who calculates an academy's budget. In either case, academies would certainly need representation on Schools Forums in order to ensure their views are heard.

As stated in Section 2, free schools are currently funded on the basis of a separate formula that seeks to approximate local authority formulae in a simple and transparent fashion. In its consultation, the government proposed that free schools should eventually receive the same level of funding as implied by the new, simpler, local authority formulae in their area. This seems a sensible approach.

\subsection{Conclusion}

This section has considered various aspects of the design of the national funding formula. The first key consideration is, of course, whether one should have a national funding formula at all. If one feels that a national funding formula for schools is desirable, then the next questions are about what it should contain. The first set of arguments concern the basic amount per pupil. There are arguments both for and against harmonising the relative funding ratio between secondary and primary schools across local authorities. On the one hand, differences in funding ratios may reflect local authorities' specific circumstances or their own strategic priorities (such as which age groups to target financial resources on). Local discretion may therefore be an important factor. On the other hand, restricting all local authorities to a similar relative funding ratio may help facilitate comparisons of their effectiveness, which in turn may be valuable to the government if it has a preference for the development of marketstyle incentives. 
Nevertheless, it is also the case that the consultation's suggested ratio of 1.27, if combined with its suggested lump sum for primary schools of $£ 95,000$, could lead to a significant redistribution of funding from secondary to primary schools. If this is not the intended outcome, then it will be necessary to adjust the basic per-pupil amounts at primary and secondary schools or the lump sum accordingly.

Another key consideration is how to account for differential costs of hiring staff. This section has shown that the updated GLM approach, which is based on general wages in the local labour market, will reinforce the generosity of funding that Inner London and the South East currently enjoy relative to other parts of the country. By contrast, switching to an approach that also reflects the actual costs of employing teachers would heavily penalise such areas (and the South more generally), but would not penalise Outer London - which, it can be argued, has been penalised by the existing system. The GLM method could be justified on the basis of issues regarding teacher recruitment and retention in areas such as Inner London. However, if such issues exist, the teacher pay structure in such areas might also merit reconsideration, especially if one believes that head teachers do not possess enough freedom with regard to teacher pay.

\section{Empirical analysis}

The previous section discussed the various options available in terms of the development of a national funding formula. Here we seek to demonstrate empirically the implications of various options for a schoollevel national funding formula. The assumptions we make, and why we make them, are clearly expressed throughout.

The consultation on school funding reform asked for views on the contents of a school-level formula; the DfE is yet to publish its response to these views. It also asked for views on how much discretion local authorities should have, and indeed whether there should be a school-level formula at all. This uncertainty means that any attempt to model the effects of the proposed reforms is likely to be speculative.

That caveat aside, the analysis will demonstrate the potential effects of different options for a national funding formula on the funding levels of individual schools (assuming local authorities do not significantly deviate from these allocations). We assume the reform is implemented in 2014-15 and assess changes relative to funding in 2014-15 based on unchanged policy, in order to focus on the effect of a national funding formula.

In a small number of cases, we also assess the changes relative to current funding levels in 2010-11. This allows us to consider the combined effect of the reforms and the planned changes to school funding. 
Depending on how much discretion local authorities exercise, they could deviate from these school-level allocations by giving some schools more, but only if other schools in the local authority receive less. We thus also discuss the effects of the proposed reforms at the regional and local authority levels. This will show more clearly which areas are likely to see the largest changes in funding as a result of the proposed reforms, and thus which areas are likely to be under the most pressure.

The government has produced a funding formula for free schools from September 2011. There is local variation in this formula: while it is always based on the same factors (number of pupils, number of FSM pupils, number of SEN pupils and so forth), the monetary amount attached to each factor varies. It is set equal to the current level of funding in that local authority for that factor. In other words, the free school formula reflects the local discretion in current fair-funding formulae.

We consider the effects of implementing this formula for maintained schools in 2011-12. Doing so allows us to answer two questions: (i) Is the free school funding formula more or less generous than funding for maintained schools? (ii) What would be the effect of the proposed reforms if current patterns of local discretion with regard to funding factors were retained? Both are crucial questions for policymakers.

Any such reforms will need to be phased in over time. Thus, in Section 5, we discuss issues relating to transition to a new formula.

\subsection{Methodology for school-level analysis}

We analyse the reforms as if they were in place in 2014-15. This is a pragmatic assumption, not a judgement about whether they should be implemented in 2013-14 or 2014-15. We then calculate schools' expected 2014-15 funding levels under existing policy, i.e. if no formula is implemented. This is the same calculation as the one made in Section 2. In particular, we assume a pupil premium worth $£ 1,900$ per pupil eligible for FSM, on top of a cash-terms freeze in existing spending per pupil. We also assume that primary and secondary pupil numbers grow in line with national projections (with differential growth by FSM eligibility status in 2011-12, as per the January 2011 School Census). This leads to 9.4\% growth in cash-terms funding per pupil. It is slightly less than current spending plans imply, largely because we are not able to allocate to schools the pupil premiums for service children and children in care.

We then calculate school funding levels under alternative policy options. To do so, we start with the pupil characteristics and numbers projected forwards above. We also keep the same envelope for revenue funding, allowing for a $9.4 \%$ cash-terms increase in funding per pupil. This would equate to a real-terms cut of $1.6 \%$ per pupil based on the GDP deflator. 
Throughout this analysis, we hold constant a number of factors, which we assume would take the same value in any new school funding system. ${ }^{18} \mathrm{In}$ particular, we hold constant pupil-led funding for SEN,19 any budgetary adjustments made in 2010-11 and any funding received via the Early Years Single Funding Formula (as primary schools receive some funding to deliver free nursery places for 3- and 4-year-olds). We exclude funding from the Learning and Skills Council for sixth forms and sixth-form pupils, as the proposed reforms focus on under-16 schooling.

\subsection{School-level analysis}

We begin by considering five simple options for a national funding formula. In these options, we only vary the basic amounts provided for all pupils, the level of the pupil premium and the level of the lump-sum amount. We leave the adjustment for differential labour costs (the Area Cost Adjustment or ACA) unchanged to focus solely on the effects of the above factors. Table 4.1 summarises the details of these five options, as well as their implications for individual school funding levels, relative to what would otherwise be expected in 2014-15. It also shows the same details and implications for two options that do vary the level of the ACA, which will be discussed later in this section and in Section 4.3.

For each option, Table 4.1 shows:

- the assumptions made regarding basic amounts, fixed costs and the pupil premium;

- the percentages of primary and secondary schools that see an increase in funding;

- the average change in funding levels for both primary and secondary schools;

- the average change among the $10 \%$ most deprived and $10 \%$ least deprived schools (both primary and secondary);

- the percentages of primary and secondary schools seeing 'large' gains or losses as a result of the potential reform ('large' being defined as $10 \%$ or more).

\footnotetext{
${ }^{18}$ We exclude some schools from the analysis: special schools, those that have only opened very recently, and free schools and academies with no predecessor school (as no pupil data are available). In the case of converter academies, we exclude the LACSEG from our calculations to ensure consistency with maintained schools.

${ }^{19}$ Ideally, we would only hold constant funding for Individually Assigned Resources, but this is not available in publicly-available data. We would also like to model the effects of the proposed reforms to high-needs funding; this would only be possible if we knew the precise details of local authorities' current formulae and the level of resources assigned to individual pupils.
} 


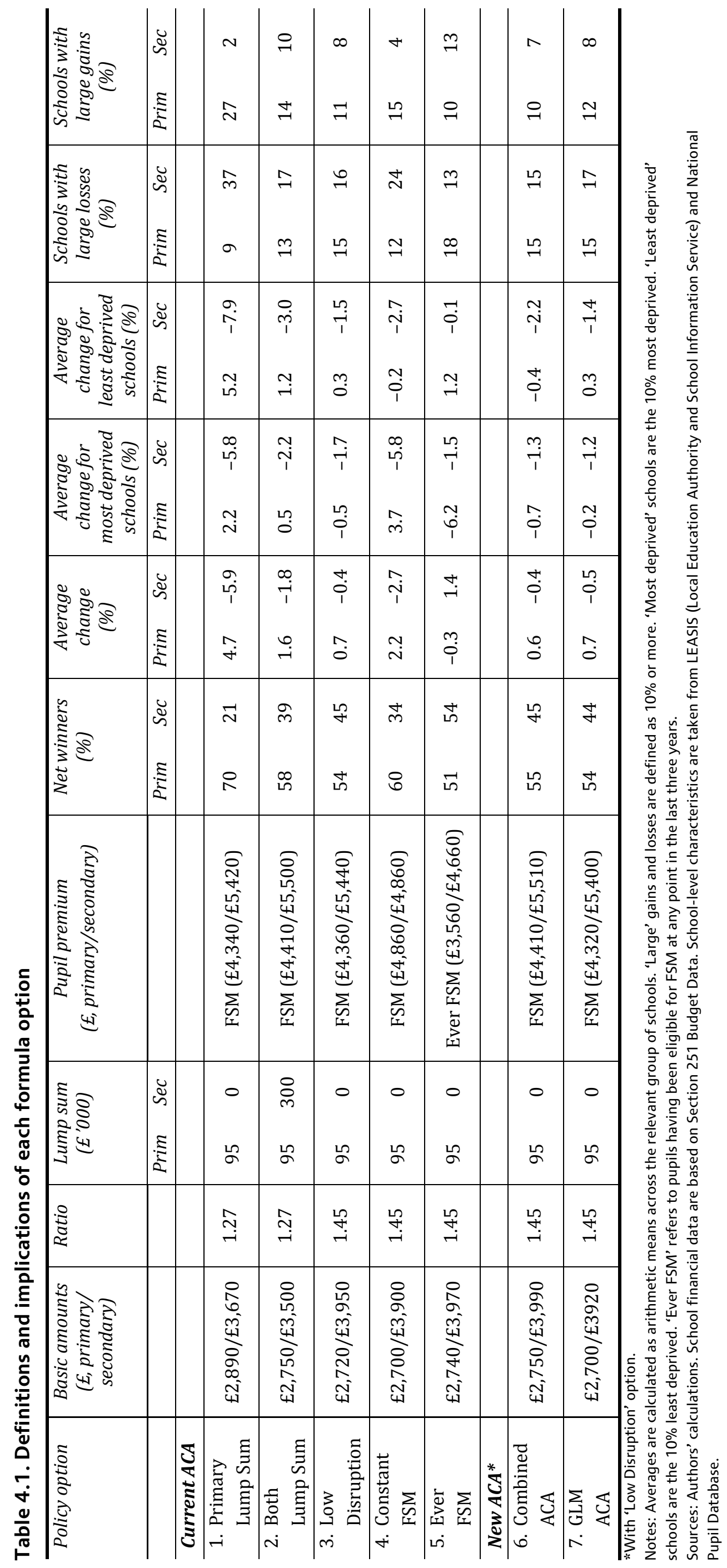


In the first option (referred to as 'Primary Lump Sum'), we consider the following specific formula:

- A ratio of 1.27 for basic per-pupil funding in secondary schools relative to primary schools. This is the centre of the proposed allowable range for local authorities and is based on current average funding levels.

- A $£ 95,000$ lump sum for primary schools.

- A pupil premium for each pupil eligible for FSM. It is 25\% greater for pupils at secondary schools than for pupils at primary schools. The levels have been set so that the formula is at least as progressive as the proposed pupil premium under current funding policy. This assumption allows us to isolate the impact of a national funding formula in itself, rather than conflating it with the introduction of the pupil premium. However, this neutrality cannot be achieved exactly; indeed, in this first option, the formula would be less progressive. This will not be the case in other options.

- As stated, we leave the ACA unchanged in order to focus solely on the effects of the above factors.

- As in all other options, the total level of school funding is set equal to the total expected in 2014-15 under existing policy.

Under this first option, there would be substantial redistribution from secondary to primary schools: primary schools would, on average, experience gains of $4.7 \%$ in funding, while secondary schools would see an average loss of $5.9 \%$. Nearly $40 \%$ of secondary schools, and less than $10 \%$ of primary schools, would see losses of $10 \%$ or more. This option is clearly far more generous to primary schools than the present system. The consultation did not articulate a desire to implement redistribution from secondary to primary schools of this magnitude; we therefore go on to consider formula options that are more generous to secondary schools.

In the second option ('Both Lump Sum'), we add a lump sum of $£ 300,000$ for secondary schools. This reduces the per-pupil amounts that can be provided; even with this high lump sum, there is still redistribution from secondary to primary schools. The pupil premium is set at similar levels to those in the first option.

In the third option ('Low Disruption'), we remove the lump sum for secondary schools and instead increase the ratio between the basic amounts for secondary and primary pupils to 1.45 . This reduces the basic amount for primary schools and increases it for secondary schools. Under this option, the redistribution from secondary to primary schools is much more modest, with primary schools only gaining $0.7 \%$, on average, and secondary schools only losing $0.4 \%$, on average. This option also roughly maintains the level of progressivity currently expected in 2014-15, as demonstrated by the fact that the average change amongst the most 
deprived primary schools is similar to the average change amongst the least deprived ones, with this pattern also holding for secondary schools.

However, $15 \%$ of primary schools would still see falls in funding of $10 \%$ or more, as would about one-sixth (16\%) of secondary schools. Smaller proportions would see large gains (about 10\% in each case). However, the proportion of schools seeing either large losses or large gains is far smaller than under the first two options, which is why we refer to this option as 'Low Disruption'.

From this analysis, it is clear that implementing a ratio of 1.27 for basic per-pupil funding at secondary schools relative to primary schools leads to significant redistribution from secondary to primary schools, if combined with the consultation's proposed $£ 95,000$ lump sum for primary schools. The consultation did not explicitly make the case for redistribution from secondary to primary schools and it thus seems likely that the government would want to adjust basic per-pupil funding ratios to prevent this. Such redistribution can be limited by using a higher secondary to primary funding ratio, such as the 1.45 employed here.

We now consider potential reforms to the pupil premium. In the next option ('Constant FSM'), we take the 'Low Disruption' option but implement the same pupil premium for primary and secondary schools (set at $£ 4,860$ per pupil eligible for FSM). This creates significant redistribution from deprived secondary schools to deprived primary schools: the former see cuts of nearly $6 \%$ while the latter experience gains of just under $4 \%$. To avoid this, the pupil premium will clearly need to be higher at secondary schools.

The government is also currently considering an extension of the pupil premium to those who have ever been eligible for FSM (in the last three or six years). Our fifth option ('Ever FSM') examines this quantitatively. It takes the 'Low Disruption' option but allocates a pupil premium for all pupils who have been eligible for FSM at any point in the last three years, rather than only in the current year. The first thing to notice is that the pupil premium is necessarily smaller - by about $£ 800$ - as it must cover more pupils. Second, the most deprived primary schools would be relative losers compared with the 'Low Disruption' option. It is important to qualify this, however, as it depends on how schools are ranked into deciles of deprivation. We have ranked schools by the proportion of pupils currently eligible for FSM; a pupil premium allocated on the same measure will, by construction, appear more progressive than a pupil premium distributed in other ways.

The main reason why deprived primary schools are the biggest losers from the 'Ever FSM' option compared with the 'Low Disruption' option is the 
effect of time: it is easier to record previous FSM eligibility for pupils who have been in the school system longer, i.e. for older pupils. In Reception or Year 1, one can only record whether children were eligible for FSM in one or two years including the current one, because they had not started school one or two years ago, respectively. For pupils currently in Year 2 onwards, information exists for all three years. While current FSM eligibility for primary and secondary pupils is $18.0 \%$ and $14.6 \%$ respectively, eligibility at any point over the last three years is $21.0 \%$ and $18.9 \%$ respectively. The increase is smaller for primary schools, so deprived primary schools lose more than deprived secondary schools do (relative to the 'Low Disruption' option).

Figure 4.1 shows how the expected change in funding per pupil under existing policy varies by school deprivation, and compares this with what would be expected under the 'Low Disruption' and 'Ever FSM' options. Specifically, it splits primary schools (panel a) and secondary schools (panel b) into deciles according to the proportion of children eligible for FSM in January 2010. The first decile contains the $10 \%$ of schools with the highest levels of current FSM eligibility, while the tenth decile contains the schools with the lowest levels of current FSM eligibility. The dark grey bars show the average levels of funding per pupil amongst schools in each decile in 2010-11. The fact that the tops of these bars slope downwards indicates that the current system is already quite 'progressive'. The light grey bars show the expected level of funding per pupil in 2014-15 under existing policy. The fact that the slope in these bars is steeper than the current pattern indicates that the pupil premium is expected to increase the level of progressivity. The solid black line shows the average percentage change in cash-terms funding per pupil for each decile, between 2010-11 and 2014-15 under existing policy. The most deprived primary and secondary schools are expected to see the highest increases in funding: $20 \%$ and $13 \%$ respectively. As a reminder, cumulative economy-wide inflation is expected to be $11.2 \%$ over this period, while cumulative schools-specific inflation is expected to be $8.4 \%$.

The dashed black line in Figure 4.1 shows the cash-terms change in funding per pupil over the same period if the 'Low Disruption' option is in place in 2014-15. The fact that this pattern is very similar to what we currently expect under existing policy arises by design and reflects our assumption that the national funding formula will maintain the expected level of progressivity in 2014-15.

The black dotted line shows the expected cash-terms change in funding per pupil under the 'Ever FSM' option. It makes clear that this option would be less progressive than both the 'Low Disruption' option and the system in 2014-15 under existing policy. Furthermore, the reduction in progressivity would be largest for primary schools. 
Figure 4.1. Change in school funding by decile of school deprivation between 2010-11 and 2014-15 under various options

\section{a) Primary schools}

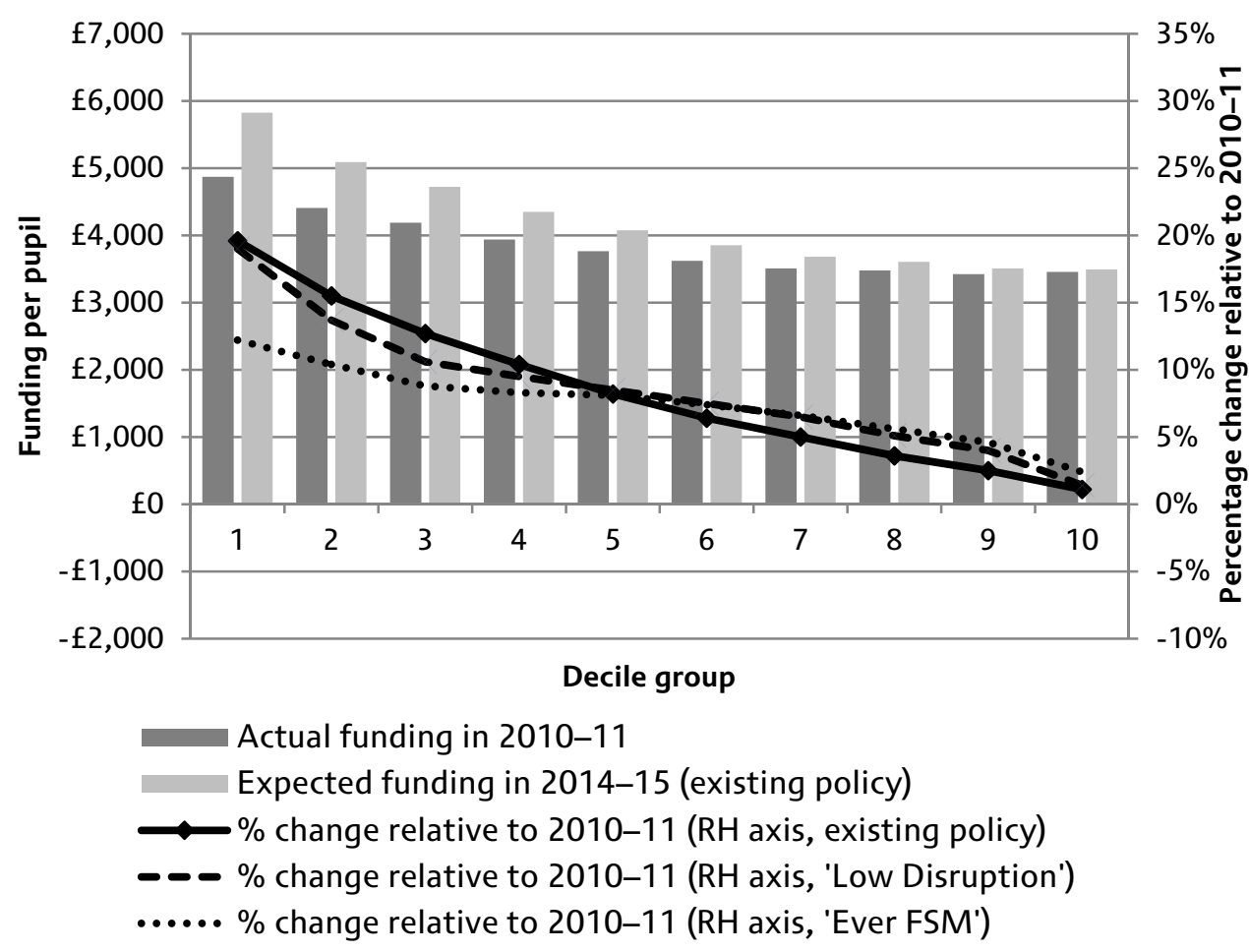

b) Secondary schools

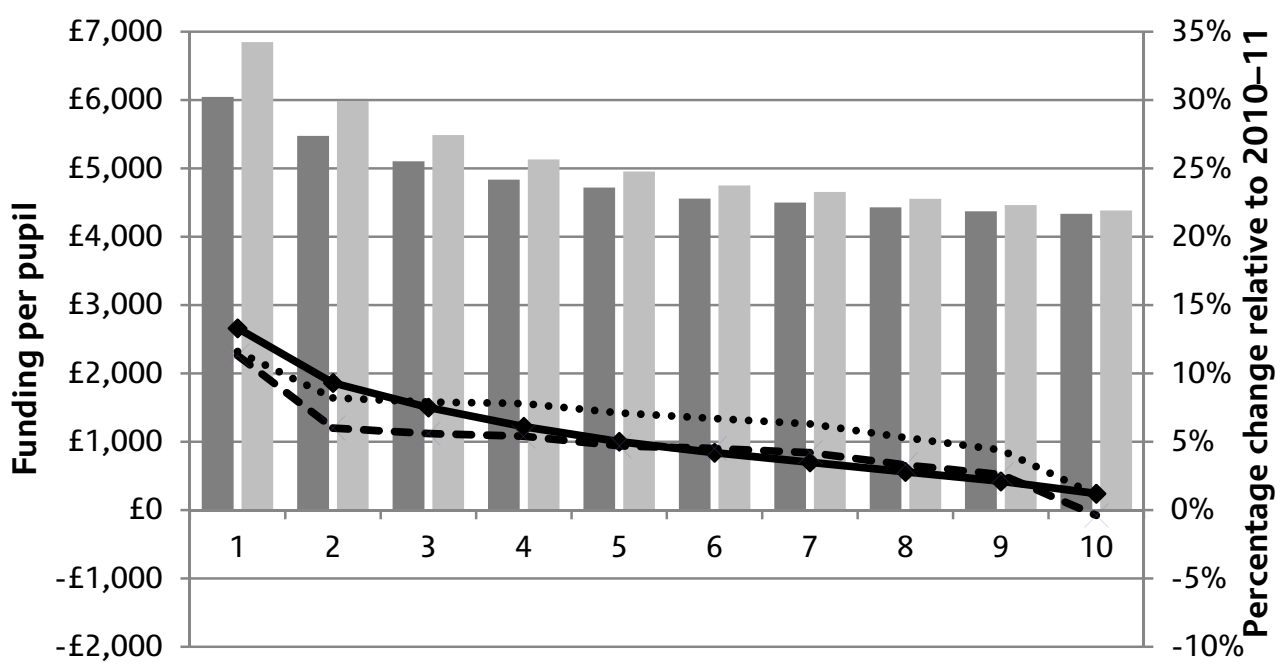

Decile group

Actual funding in 2010-11

Expected funding in 2014-15 (existing policy)

$\longrightarrow \%$ change relative to $2010-11$ (RH axis, existing policy)

- - $\%$ change relative to 2010-11 (RH axis, 'Low Disruption')

...... \% change relative to 2010-11 (RH axis, 'Ever FSM')

Sources: Authors' calculations. School financial data are based on Section 251 Budget Data. School-level characteristics are taken from LEASIS (Local Education Authority and School Information Service) and National Pupil Database. 
It should be remembered that all this analysis assumes that local authorities do not deviate from the school-level formula. The actual effects of the national formula could be different if local authorities did indeed deviate from it. However, tight restrictions on the permissible ratio between secondary and primary funding would make some redistribution from secondary to primary schools inevitable.

The above analysis also maintains the ACA uplifts at their current levels. As indicated in Section 3, a new or updated version may be desirable, given that the current one was set in the early 2000s. In the next two options, we repeat the 'Low Disruption' option with the two proposed ACAs in the consultation (the updated GLM approach and the combined approach). As is shown in Table 4.1, both are very similar to the 'Low Disruption' option in terms of the average gains and losses amongst primary and secondary schools.

Figure 4.2. Changes in school funding levels under 'Low Disruption' option with current or combined ACA factors, relative to 2014-15 levels under existing policy

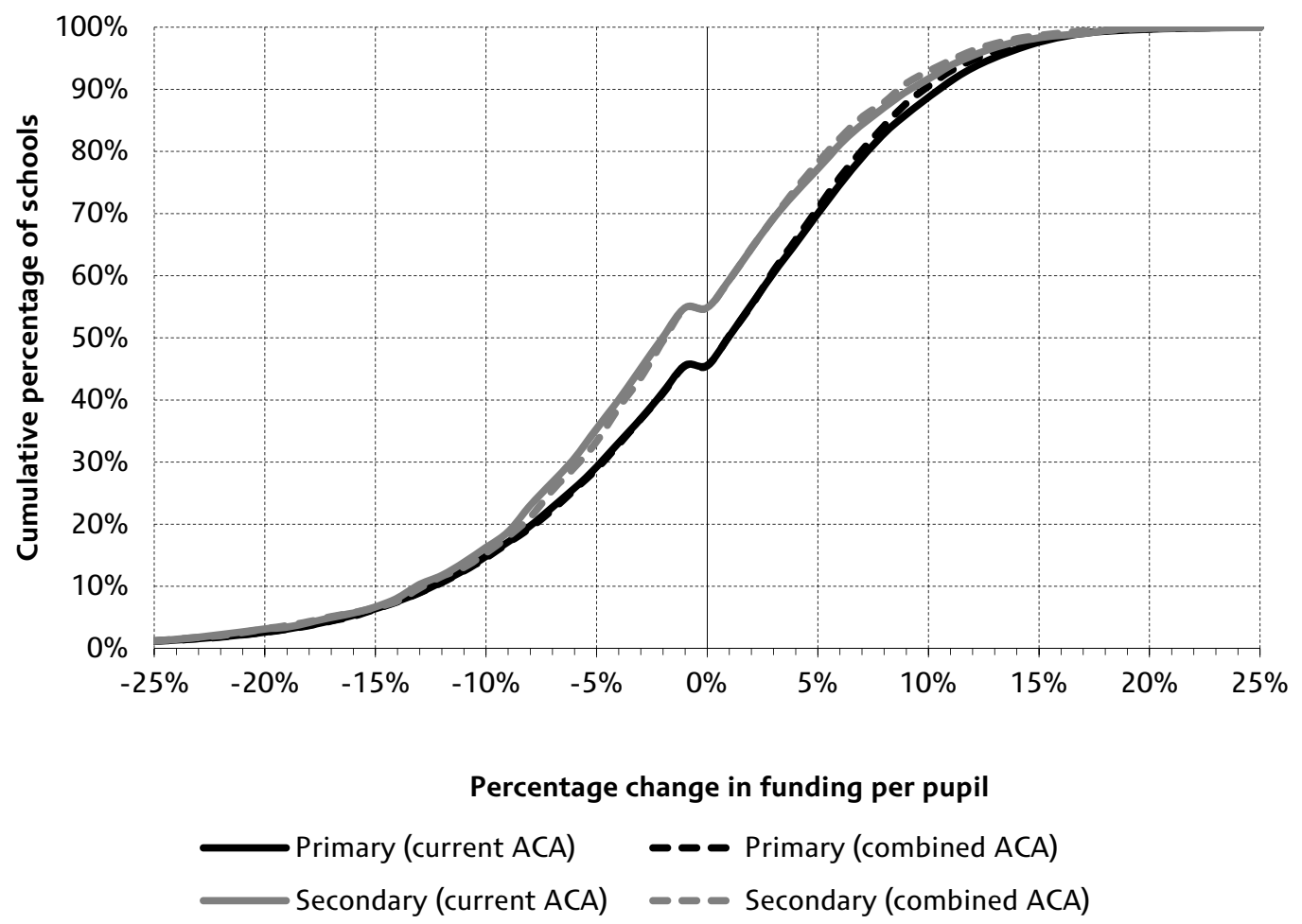

Sources: Authors' calculations. School financial data are based on Section 251 Budget Data. School-level characteristics are taken from LEASIS (Local Education Authority and School Information Service) and National Pupil Database.

We now conduct further analysis of the 'Low Disruption' option, both with the current ACA and with the combined ACA. Figure 4.2 shows the proportion of primary schools (black lines) and secondary schools (grey lines) experiencing changes in funding, relative to 2014-15 levels under existing policy, of less than a given value. The solid lines show the distribution of gains and losses for the 'Low Disruption' option with the 
current ACA; the dashed lines do the same for the 'Low Disruption' option with the combined ACA. Amongst both primary and secondary schools, the two options imply remarkably similar changes. As we have already seen, about one-sixth of primary and secondary schools would experience losses of $10 \%$ or more under these policy options. We can now also see that about a third of secondary schools would see losses of 5\% or more, as would just under $30 \%$ of primary schools. On the other hand, about a quarter of secondary schools would see gains of $5 \%$ or more under either option, as would about $30 \%$ of primary schools.

The fact that these options give a very similar overall picture is not particularly surprising. The key differences will arise when the implications at the local authority and regional levels are analysed in Section 4.3.

As we made clear earlier, existing funding policy up to 2014-15 already implies significant changes in funding across schools relative to 2010-11, as a result of the cash-terms freeze in existing spending per pupil and the creation of the pupil premium. A crucial question for schools is how the proposed reforms could interact with the changes to funding that have already been planned.

Figure 4.3 shows the distribution of the changes in school funding levels implied by the 'Low Disruption' option with the combined ACA, compared with funding in 2010-11, for (a) primary schools and (b) secondary schools. The net changes shown by the dashed lines combine the effect of this option with the planned changes in school funding up to 2014-15 under existing policy (solid lines). For reference, the graphs also show the levels of cumulative economy-wide inflation (solid vertical grey line) and schools-specific cost inflation (dashed vertical grey line).

The 'Low Disruption' option with the combined ACA leads to two differences from the planned policy changes. First, fewer schools would see real-terms cuts in funding (under either measure of inflation) compared with existing policy. However, more schools would see larger cuts in funding. In fact, over $20 \%$ of primary schools and around $30 \%$ of secondary schools would experience cash-terms reductions in funding; under current policy, no schools would experience these. 
Figure 4.3. Cash-terms changes in school funding between 2010-11 and 2014-15 under existing policy, and under 'Low Disruption' option with combined ACA

a) Primary schools

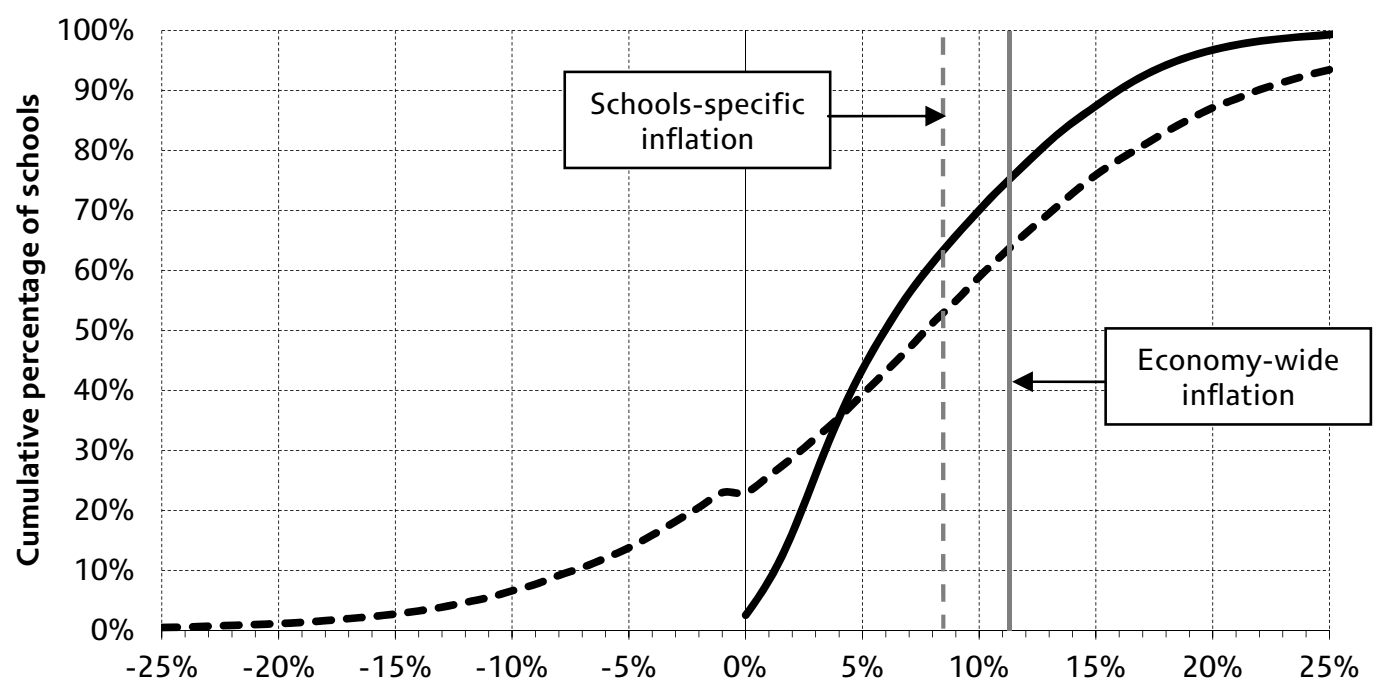

Percentage change in funding per pupil

Existing policy _ _ - 'Low Disruption' with combined ACA

b) Secondary schools

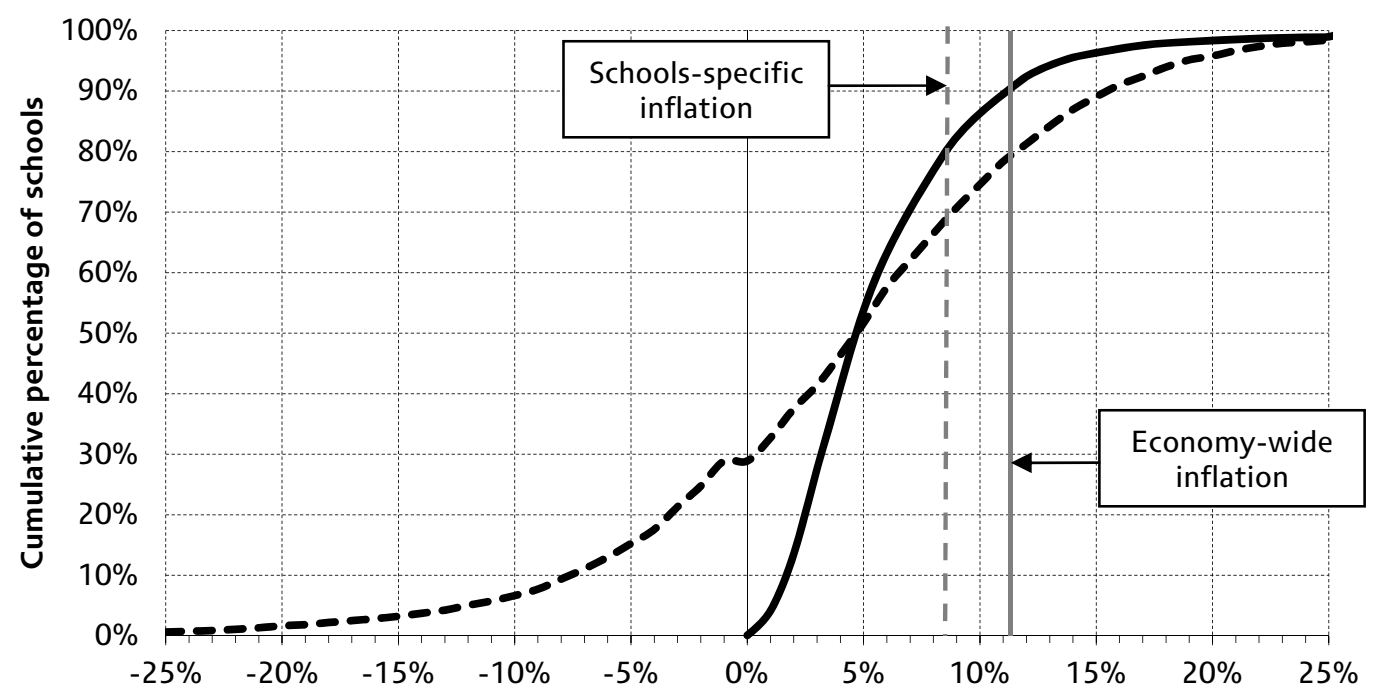

Percentage change in funding per pupil

Existing policy _ _ - 'Low Disruption' with combined ACA

Sources: Authors' calculations. School financial data are based on Section 251 Budget Data. School-level characteristics are taken from LEASIS (Local Education Authority and School Information Service) and National Pupil Database. 


\subsection{Regional analysis}

The previous section considered the impacts of moving to a national funding formula that minimised the amount of disruption to school funding levels (among all the options considered). However, even if changes at the school level are minimised, there could still be significant consequences at the local or regional level. First, local authorities currently fund similar schools in different ways, and at least some of this discretion will be curtailed under a national funding formula. Second, the proposed reforms to the ACA methodology would have significant and different consequences for the regional pattern of school funding levels, as demonstrated in Section 3.5.

The analysis in this section therefore considers the effect of these policy options at the regional and local authority levels. Figure 4.4 shows the average impact at regional level of moving to the 'Low Disruption' option under the current ACA methodology, under the new combined approach and under the updated GLM approach. This is shown separately for primary schools (panel a) and secondary schools (panel b). In each case, the impacts are relative to what the funding levels would have been in 2014-15 under existing policy with the existing ACA factors.

Both primary and secondary schools in the North East, West Midlands and Yorkshire \& the Humber would lose funding, on average, as a result of these reforms. These losses would be slightly lower under the combined ACA but slightly higher under the updated GLM ACA. In the East Midlands and the South East, both types of school would see increases in funding, on average, under the reforms. For the South East, these increases would be smaller under the combined ACA, but of similar sizes under the current and updated GLM ACAs.

Primary schools in the East of England and in the South West would experience increases in funding under all the ACA versions, but secondary schools would see little change. Secondary schools in the North West would lose funding, on average, whereas primary schools there would see little change.

Schools in Outer London would see little change, on average, under the current ACA, though they would see a slight increase in funding under the combined ACA or updated GLM. The pattern for Inner London is different and more dependent on the ACA methodology. Primary schools would see a fall in funding as a result of moving to the 'Low Disruption' option with the current ACA. This fall would be increased under the combined ACA approach but lessened under the updated GLM approach. Secondary schools, on the other hand, would see increases in funding, and such increases would be noticeably higher under the updated GLM approach. 
Figure 4.4. Region-level change in school funding in 2014-15 under 'Low Disruption' option with different ACA factors, compared with expected funding in 2014-15 under existing policy

a) Primary schools

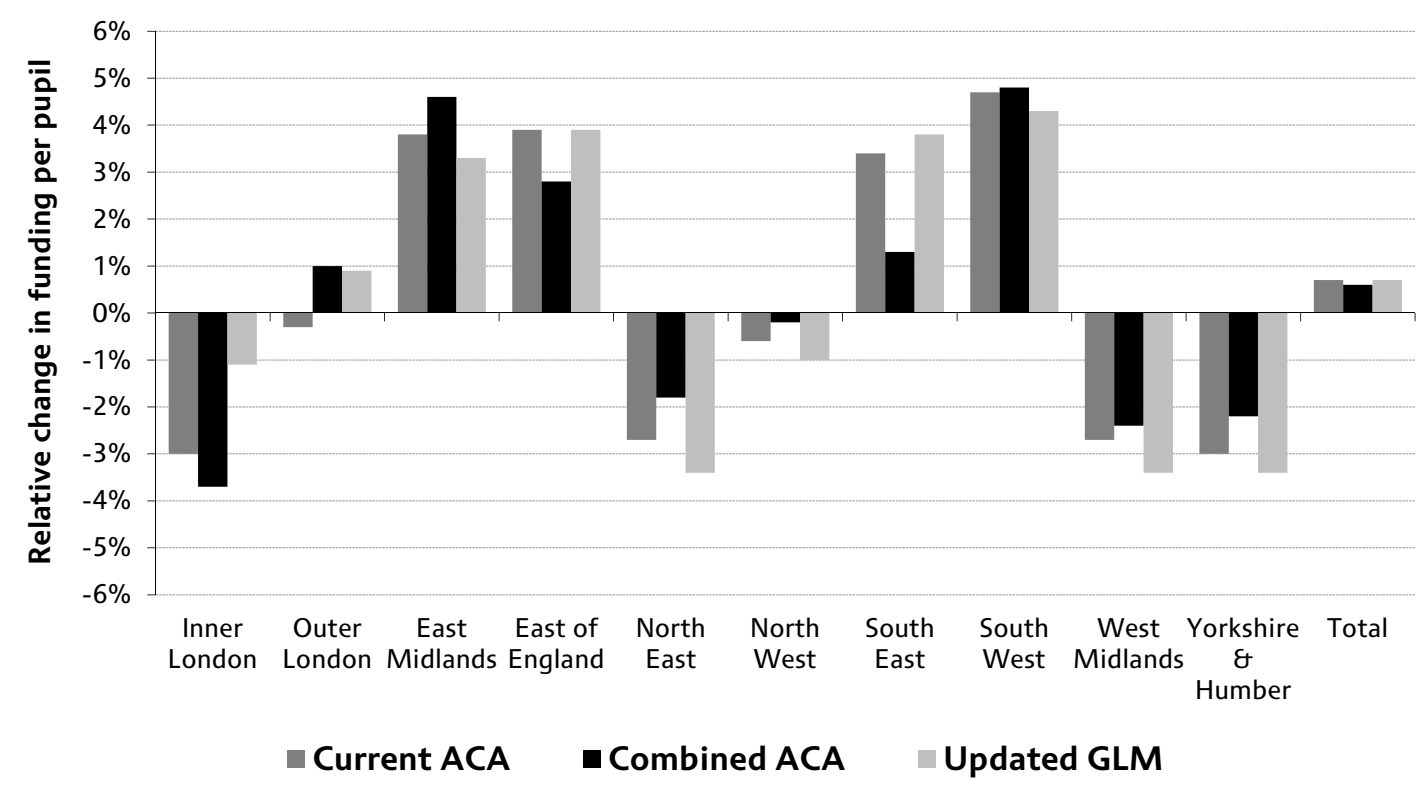

\section{b) Secondary schools}

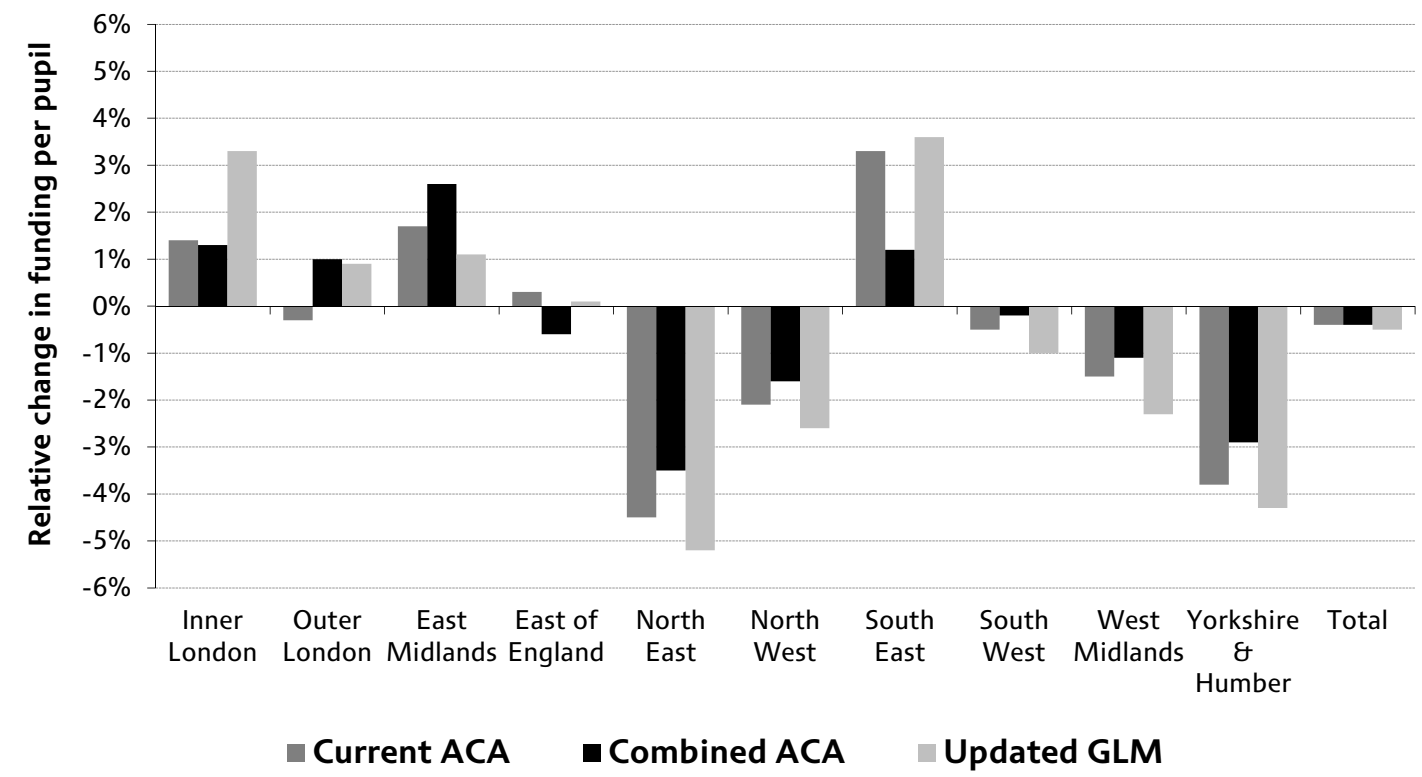

Sources: Authors' calculations. School financial data are based on Section 251 Budget Data. School-level characteristics are taken from LEASIS (Local Education Authority and School Information Service) and National Pupil Database.

We can thus draw out a number of general patterns. First, in some regions (North East, West Midlands and Yorkshire \& the Humber), there would be falls in funding as a result of a national funding formula such as the 'Low Disruption' option. If one believes that a simple national funding formula, such as that described by the 'Low Disruption' option, represents an 
appropriate system of school funding, then these results would imply that schools in these regions are currently over-funded on average. In other regions (East Midlands and South East), schools would see an increase in funding; these might be deemed to have been under-funded under current policy if a national funding formula is preferred. For other regions outside of London, the picture differs between primary and secondary schools. Outer London would see very small changes on average.

In most cases, changing the ACA methodology has little impact on the magnitude or direction of the effect. The impact of changing the ACA methodology is largest for London and the South East. Any change in the ACA would benefit schools in Outer London. Schools in Inner London would see increases in funding under the updated GLM ACA, while schools in the South East would lose funding as a result of moving to the combined approach for the ACA.

Nevertheless, in all cases, the changes by region are small: less than $5 \%$, on average. We now turn to average changes by local authority, as the size of these effects seems likely to drive most of the regional patterns we observe. This is naturally an even more speculative exercise than the analysis presented up to now. However, such analysis can still be informative about the extent to which changes in funding are likely to be concentrated in particular local authorities and which local authorities are likely to receive the largest changes.

Figure 4.5 plots the average changes in funding under the 'Low Disruption' option with the combined ACA amongst primary schools (panel a) and secondary schools (panel b) in different local authorities. In each case, the changes are ordered from highest to lowest. Again, the changes are presented relative to the expected funding levels in 2014-15 under existing policy. Appendix Table A.5 shows the underlying data for these graphs, along with the expected average changes under the current and updated GLM ACAs.

The first point to notice is that the spread of changes at local authority level is much wider than the spread by region, and there are a small number of local authorities where large gains or losses are felt. This pattern is likely to be driven by a number of factors. First, some local authorities will currently have higher or lower levels of funding for both primary and secondary schools than those implied by a single national funding formula. If one believes that the latter represent an appropriate system of school funding, then these local authorities could be described as over- or under-funded at present. Alternatively, one might believe that the current system reflects local knowledge and is preferable. In this case, if some local authorities lose or gain funding, the interpretation would be that the school factors upon which the formula is based (such as the 
number of pupils eligible for FSM) do not capture the true educational needs of the schools in those areas.

Figure 4.5. Local-authority-level change in school funding in 2014-15 under 'Low Disruption' option with combined ACA, compared with expected funding in 201415 under existing policy

a) Primary schools

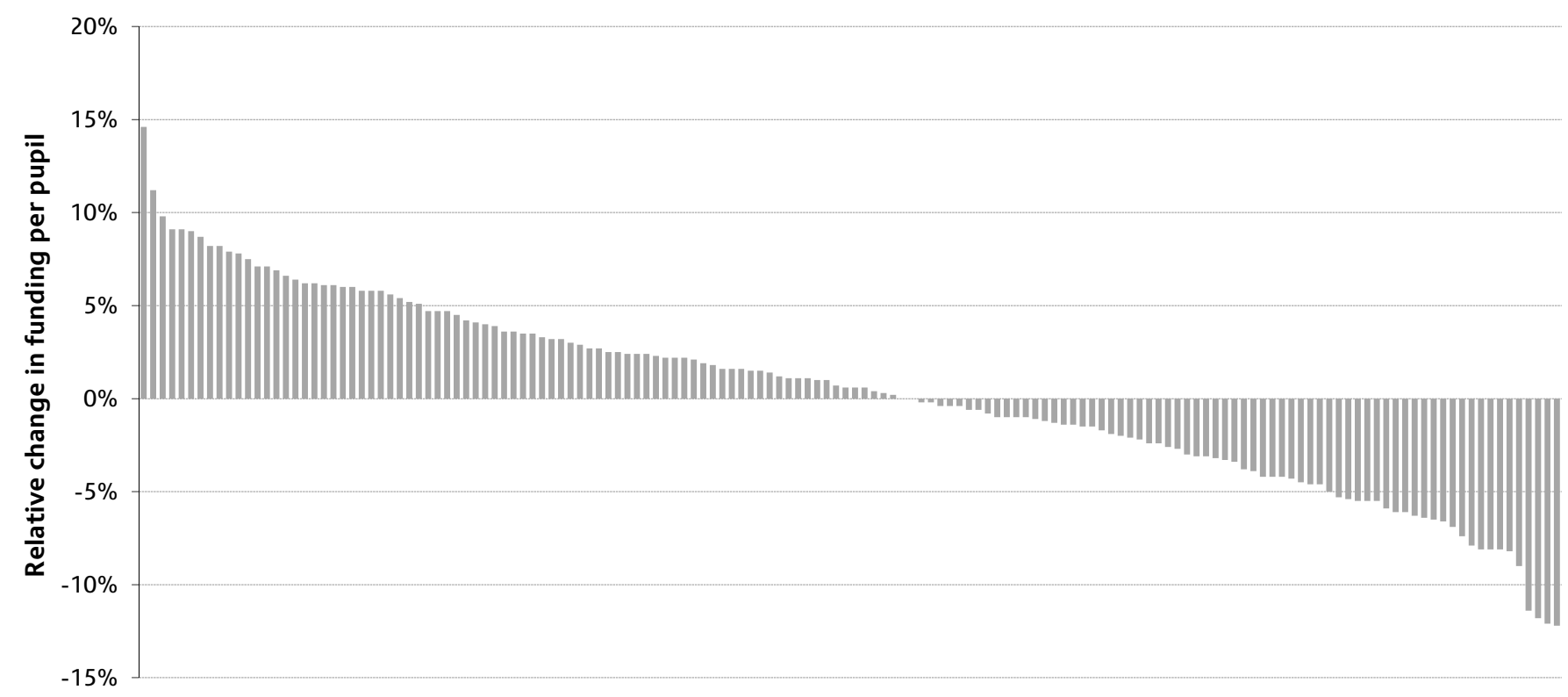

b) Secondary schools

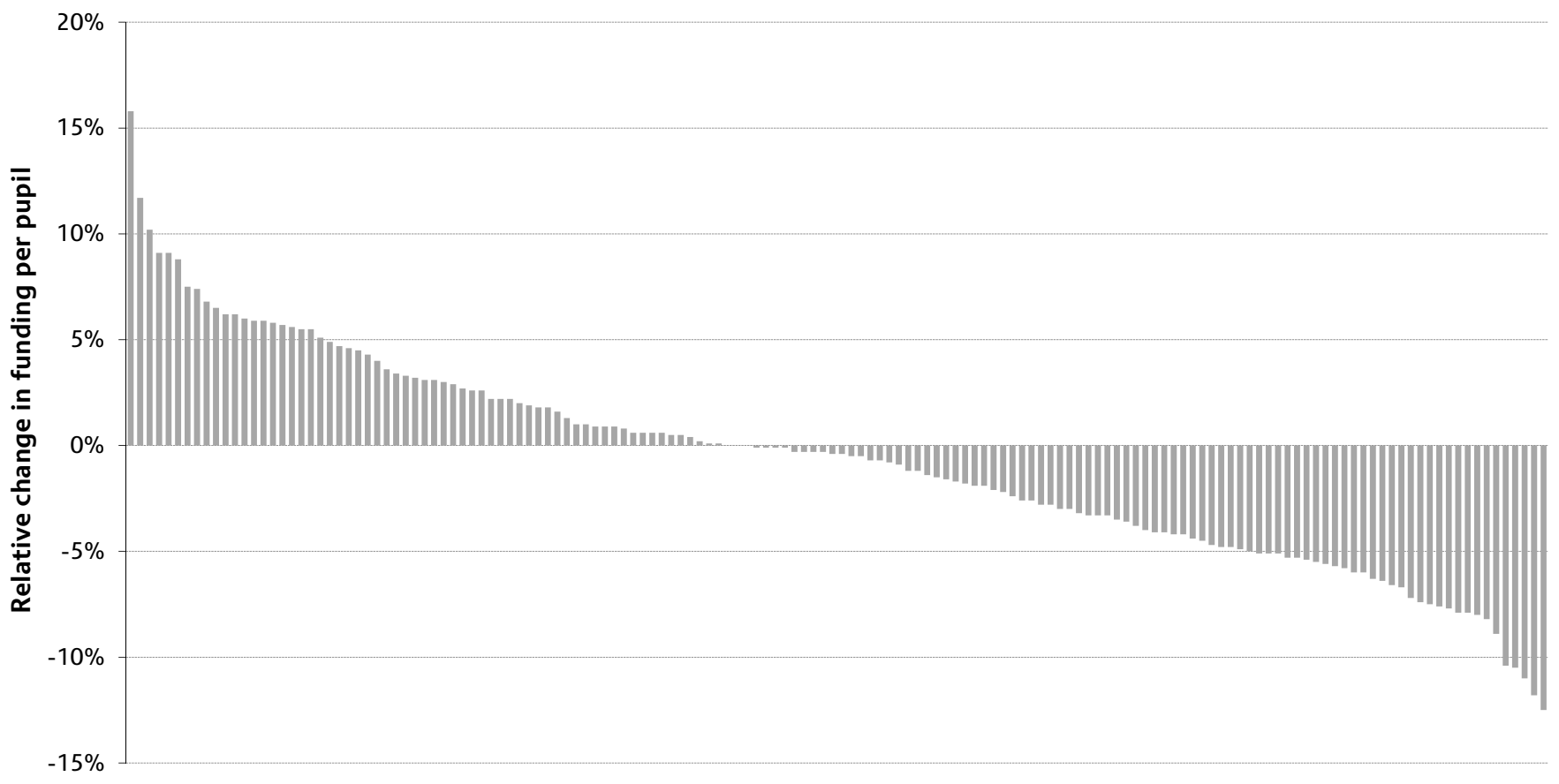

Sources: Authors' calculations. School financial data are based on Section 251 Budget Data. School-level characteristics are taken from LEASIS (Local Education Authority and School Information Service) and National Pupil Database. 
Although this is not obvious from Figure 4.5, there is actually only a weak association between the change in funding for a local authority's primary schools and the change in funding for its secondary schools. ${ }^{20}$ This points to another important driving force behind the patterns that are observed. A national funding formula would harmonise the secondary to primary school funding ratio across local authorities. Hence secondary schools in local authorities with a higher-than-average ratio of secondary to primary funding would lose, on average, while primary schools in such local authorities would experience an increase in funding, on average. This pattern would be reversed in local authorities where the secondary to primary funding ratio is below the national average.

Another potential explanation for changes by local authority is the fact that some local authorities choose to retain different amounts to spend on central services. Our analysis does not take such differences into account. However, as our analysis in Section 3.7 showed, a large proportion of these differences relate to spending on high-needs pupils; pupil-led funding for pupils with SEN is held constant in our analysis.

As already stated, the exact changes by local authority under the 'Low Disruption' option are shown in Appendix Table A.5. The most important point to notice is that the average changes are largely constant across the three different ACA methodologies. The exceptions to this are to be expected from the previous regional analysis. Schools in Inner London would benefit more from the updated GLM methodology (though Haringey and Newham would actually benefit more from the combined approach). Schools in Outer London would, by and large, benefit from any change to the ACA. Schools in the South East would generally lose from moving to the combined ACA approach, particularly in areas just outside London (for example, Reading, Surrey and West Berkshire).

Looking at Table A.5, we observe that under all three scenarios, the largest increases in funding for primary schools are in Bromley and South Gloucestershire (over 10\% in all cases). The largest falls in primary school funding are in Bradford, the Isle of Wight, Luton, Newham and Southwark (over $10 \%$ in almost all cases). Amongst secondary schools, the largest increases are in Buckinghamshire, Merton and Sutton (over 10\% in almost all cases), whilst the largest falls are in Liverpool, Rotherham and Wolverhampton (over $10 \%$ in all cases). Which local authorities see the most extreme changes in funding therefore depends on whether primary or secondary schools are considered. Hence harmonising the ratio of

\footnotetext{
${ }^{20}$ The correlation coefficient between funding changes for primary and secondary schools ranges from 0.45 to 0.58 depending on the ACA regime.
} 
secondary to primary school funding drives some of the average changes observed across local authorities.

However, there are also some local authorities that see consistently large increases amongst both primary and secondary schools, and some that see consistently large falls. Primary and secondary schools in Coventry, Liverpool, North East Lincolnshire, Wigan and Wolverhampton would see average falls of $6 \%$ or more under all three ACA methods, while primary and secondary schools in Derbyshire, Islington and Warwickshire would see average increases of $6 \%$ or more. If one believes that a single national funding formula represents an appropriate system of school funding, such local authorities would be deemed to be currently over- or under-funded respectively. Alternatively, one might believe that these local authorities have higher or lower levels of educational need than those implied by the factors upon which a national formula might be based.

\subsection{Free school formula}

The government has also published the proposed funding formula for free schools in 2011-12. This is based on a small set of locally-varying factors and aims to mimic the current average local authority funding of maintained schools in order to ensure that free schools are funded on the same basis as similar maintained schools in the same area. First, the formula allocates a lump sum of $£ 95,000$ for all primary schools (as the most recent consultation proposed). Second, based on funding levels in 2010-11, it calculates a level of basic funding per pupil and a level of funding targeted at pupils eligible for FSM (excluding the costs of the lump sum). These levels differ across local authorities. In addition, free schools will also receive the national pupil premium amounts, including $£ 488$ for pupils eligible for free school meals. Lastly, in a similar vein to academies, free schools will also receive additional funding to reflect the fact that they are responsible for services that would be provided for maintained schools by local authorities.

Since free schools are new establishments, it is not possible to measure the effect of the funding formula relative to funding in previous years. Instead, to illustrate its effect, we apply it to all current schools and compare the funding levels that result with the funding levels that schools would have had in 2011-12 under current policy. ${ }^{21}$ This process demonstrates the overall generosity of the free school formula relative to current funding

\footnotetext{
${ }^{21}$ This exercise cannot be conducted for other years because the formula is only available for 2011-12.
} 
arrangements. ${ }^{22}$ Since the factors in the formula vary by local authority, the formula can also be interpreted as a sign of what a future national funding formula might look like if all local authorities were to exercise as much discretion as possible.

Figure 4.6 shows the distribution of changes in funding levels that would arise if all schools were funded according to the free school formula for 2011-12, relative to current funding levels for 2011-12. The black line illustrates the distribution for primary schools, while the grey one corresponds to secondary schools. The formula is, on balance, slightly more generous to primary schools than secondary schools: over $60 \%$ of primary schools would see an increase in funding as a free school, compared with only half of secondary schools. A quarter of secondary schools would experience a significant loss of funding (at least 5\%), compared with about one-sixth of primary schools. At the other end of the scale, one in ten primary and secondary schools would see large increases in funding, of $10 \%$ or more.

Figure 4.6. Changes in school funding under free school formula, relative to 2011-12 funding levels under existing policy

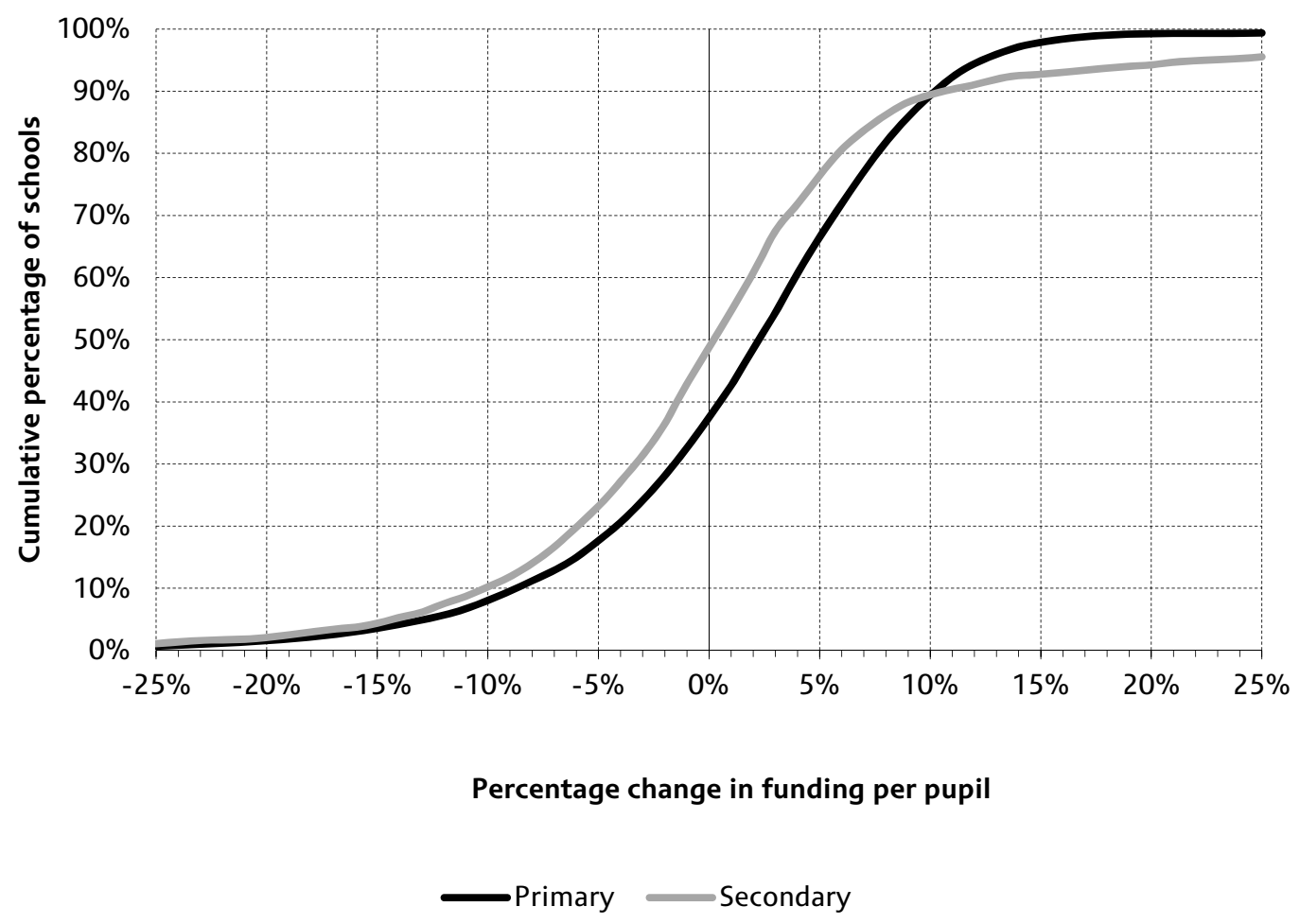

Sources: Authors' calculations. School financial data are based on Section 251 Budget Data. School-level characteristics are taken from LEASIS (Local Education Authority and School Information Service) and National Pupil Database.

${ }^{22}$ At this stage, it is important to note that we include the LACSEG and SEN elements within the baseline for maintained schools. As such, current funding should be interpreted as current funding plus LACSEG and SEN elements per pupil. 
Figure 4.7. Change in school funding under free school formula, relative to 2011-12 funding levels under existing policy, by decile of school deprivation

a) Primary schools

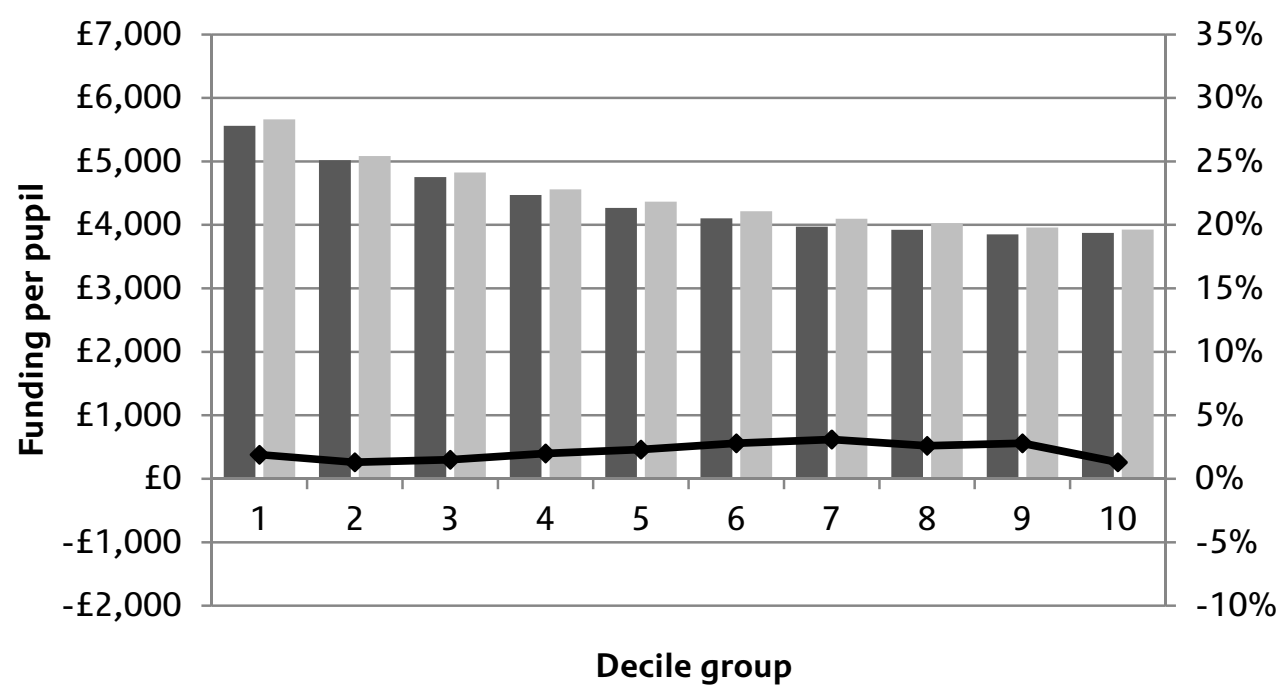

Actual funding in 2011-12

Funding in 2011-12 under free school formula

—\% change relative to actual 2011-12 funding (RH axis)

\section{b) Secondary schools}

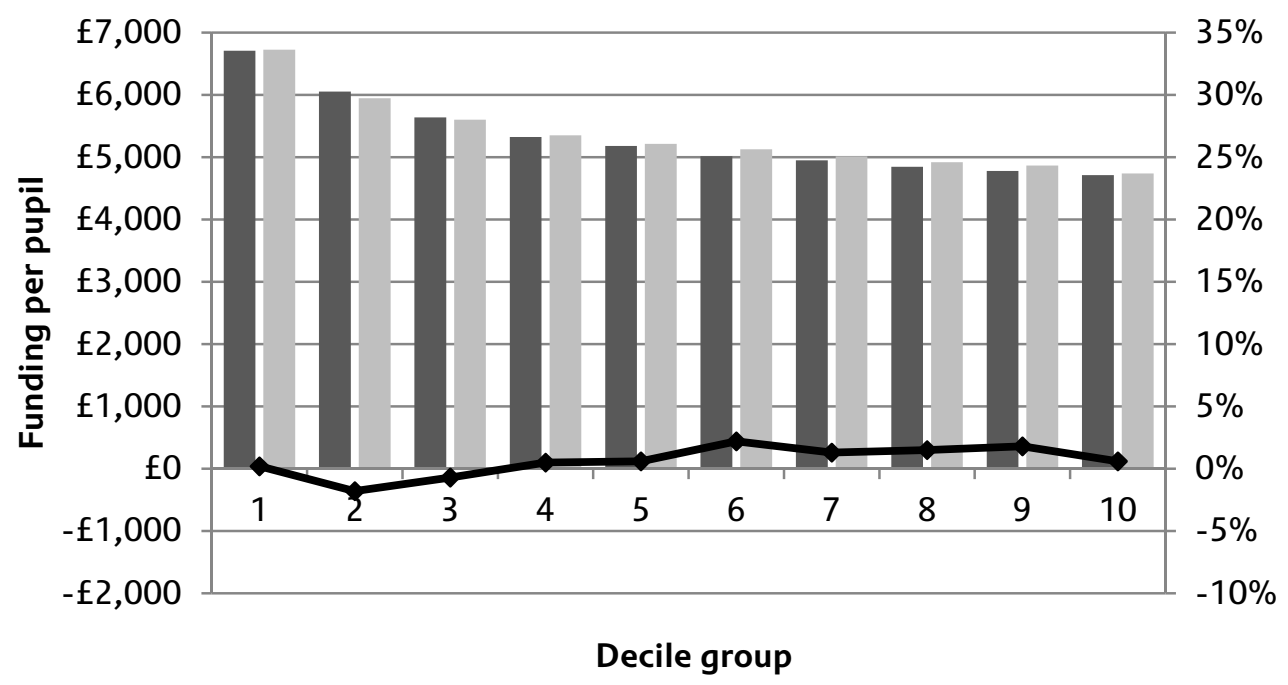
are taken from LEASIS (Local Education Authority and School Information Service) and National Pupil Database. 
In the round, the free school formula is slightly more generous than current funding arrangements. The hypothetical extra cost is small in the sense that the difference between the current funding of maintained schools and what they might receive as a free school is only around $1 \%$, on average. However, this is actually an underestimate, since free schools would also receive SEN funding in the form of Individually Assigned Resources, which is on top of the formula funding (as it is attached to particular pupils).

To assess the relative progressivity of the proposed free school formula, we return to the decile charts of school funding. In Figure 4.7, the dark grey bars show the current levels of school funding in 2011-12 by deprivation decile, for (a) primary schools and (b) secondary schools. The light grey bars show what funding levels by decile would look like if all such schools were subject to the free school formula. The black line then plots, on the right-hand axis, the relative change in funding levels for each decile.

Generally, the differences between actual funding and funding under the free school formula are very small for each decile. Primary schools appear to be on average better off across all deciles, but those that are less deprived seem to benefit by slightly more than those that are more deprived. Meanwhile, many deprived secondary schools (those in deciles 2 and 3) would be made slightly worse off by the free school formula, while more affluent secondary schools would be slightly better off. Hence the free school formula appears to be slightly less progressive than current funding allocations.

Overall, therefore, if the free school formula were applied universally, it would lead to a slightly more expensive and slightly less progressive funding system than that which is planned under existing arrangements. However, the differences are relatively small.

\subsection{Conclusion}

This section has quantified the implications of moving to a national funding formula in a manner that is revenue-neutral and which does not affect the degree of progressivity in the distribution of school funding after the pupil premium has been implemented.

The first key message from this analysis is that the specific monetary amounts involved in a formula must be chosen extremely carefully, if significant disruption to school finances (or redistribution between different types of school) is not a desired outcome of the reform. In particular, we have demonstrated that any formula that combines a ratio of secondary to primary funding of 1.27 with a $£ 95,000$ lump sum for primary schools leads, on balance, to gains among primary schools but 
losses among secondary schools. To alleviate this, the funding ratio should be more heavily geared towards secondary school pupils. In our analysis, we find that a ratio of 1.45 minimises the redistribution from secondary to primary schools.

It is important to recognise as well that current levels of deprivation funding are also geared more strongly towards secondary schools. A formula that aimed to minimise disruption would thus need to implement a higher pupil premium for secondary schools than for primary schools. In total, we calculate that a pupil premium would need to be about $£ 4,400$ per primary pupil and $£ 5,400$ per secondary pupil in order to maintain the planned degree of progressivity in the school funding system.

We have also examined the potential effects of implementing a pupil premium for those who have ever been eligible for free school meals in the last three years. This would cover more pupils than a pupil premium based only on current FSM eligibility, making the overall value of the pupil premium smaller. Hence the system would become less progressive (particularly for primary schools).

Even with careful design to minimise disruption, it is inevitable that there will be large numbers of winners and losers. About one-sixth of primary and secondary schools would see losses of $10 \%$ or more, while around one in ten would see gains of $10 \%$ or more. Such changes would be the result of greater harmonisation across local authorities. Combining the effects of moving to a national formula with the existing plans for school funding, we find that around $7 \%$ of schools would see cash-terms reductions in funding of at least $10 \%$ between $2010-11$ and $2014-15$. This is clearly a worse outcome for those schools than the alternative (under existing policy) of at worst a cash-terms freeze. However, it is important to reiterate that current policy would lead to funding per pupil becoming less transparent over time, continuing the trend since 2006.

Combining the 'Low Disruption' reform with changes to the ACA methodology also has significant implications at a regional level. On average, the South East and the East Midlands would benefit overall, while the North East, West Midlands and Yorkshire \& the Humber would lose out.

Changes in funding will be concentrated in particular areas, with average gains and losses being more than $10 \%$ in some local authorities. In some cases, the changes amongst primary and secondary schools are offsetting, simply reflecting greater harmonisation across local authorities in the ratio of secondary to primary school funding. In other cases, both primary and secondary schools are expected to see large changes in funding. If one believes that a single national funding formula represents an appropriate 
system of school funding, then such local authorities would be deemed to be currently over- or under-funded. Alternatively, one might believe that these local authorities have higher or lower levels of educational need than those implied by the factors upon which a national formula might be based.

Whatever formula is chosen, it will lead to a large number of winners and losers relative to existing policy, unless local authorities have complete discretion to set schools' allocations. This situation is an inevitable consequence of replacing the current system, where funding levels can be based on myriad historical and local factors, by a streamlined version where funding is more transparent and consistent across the country.

\section{Transitional arrangements}

The previous section demonstrated the eventual impact (as if it had occurred in 2014-15) of moving to a national funding formula, for a version of the formula that implies the least disruption among all the options considered ('Low Disruption'). Even so, some schools would experience significant turbulence in their funding levels under this option: Figure 4.3 demonstrated that a considerable proportion of schools would see cash-terms reductions in their funding per pupil.

What Section 4 did not discuss is how long it might take to implement such a formula in order to make the transition to the new funding levels as smooth as possible, and the effects in the intervening years. We now explore these issues.

\subsection{The costs of transition}

The main way to smooth the transition from the current system to a national funding formula would be to impose a floor on the annual change in funding per pupil that a school might experience. For example, a floor of $-5 \%$ would mean that no school could experience a reduction in funding per pupil of more than $5 \%$. Imposing a floor clearly increases the time required for all schools to arrive at the allocations determined by the national funding formula, but it provides a more stable and consistent path towards the eventual allocation. The recent consultation considered a cash-terms floor (using the Minimum Funding Guarantee) of $-1.5 \%$ per year.

We have addressed this issue by calculating, for a range of potential cashterms floors from $-1 \%$ to $-10 \%$, how long it would take for all schools to reach the allocations given by the 'Low Disruption' option with the combined ACA. This analysis is presented in Table 5.1. 
Table 5.1. Possible durations and costs of transition under 'Low Disruption' option with combined ACA

\begin{tabular}{r|ccc}
\hline $\begin{array}{r}\text { Floor on annual } \\
\text { cash-terms loss } \\
\text { in funding per } \\
\text { pupil }\end{array}$ & $\begin{array}{c}\text { Length of } \\
\text { transition } \\
\text { (years) }\end{array}$ & $\begin{array}{r}\text { Cumulative total cost of transition } \\
\text { (fm, cash terms) } \\
\text { With ceiling of } \\
\text { Without ceiling on } \\
\text { increases in funding }\end{array}$ & $\begin{array}{r}\text { 10\% } \text { year } \\
-1 \%\end{array}$ \\
$-2 \%$ & 15 & 5,896 & 3,204 \\
$-3 \%$ & 10 & 2,699 & 1,216 \\
$-4 \%$ & 8 & 1,641 & 561 \\
$-5 \%$ & 6 & 1,124 & 462 \\
$-6 \%$ & 5 & 811 & 377 \\
$-7 \%$ & 5 & 609 & 303 \\
$-8 \%$ & 4 & 474 & 240 \\
$-9 \%$ & 4 & 370 & 187 \\
$-10 \%$ & 3 & 296 & 142 \\
\hline
\end{tabular}

Sources: Authors' calculations. School financial data are based on Section 251 Budget Data. School-level characteristics are taken from LEASIS (Local Education Authority and School Information Service) and National Pupil Database.

The first column contains the potential value of the floor. The second column features the number of years that would be required for all schools to reach their formula allocations, given the floor that has been implemented. Naturally, the smaller the floor (that is, the closer it is to zero), the more losses are deferred to future years. Thus, with a smaller floor, it takes longer for schools to complete the adjustment process. With an annual cash-terms floor of $-1 \%$ per year, it would take 30 years to reach the formula allocations (i.e. by 2044 if starting in 2014), whereas it would only take three years with a floor of $-10 \%$ per year. In between these, it would take six years to reach the new formula if schools were allowed to lose up to $5 \%$ of their cash-terms funding per pupil annually. If such a transition were to begin in 2014-15, then $99 \%$ of schools would be on the new formula by 2020 .

The third column of Table 5.1 shows the cumulative additional spending required while maintaining a given floor over the years that it is needed. For instance, imposing a cash-terms floor of $-5 \%$ per year would cost a cumulative total of about $£ 810$ million over six years (or $£ 135$ million a year) in cash terms. The additional spending is required to limit the cuts in individual schools' budgets to 5\%, instead of the larger cuts that the formula might imply. It is clear by now that the floor of $-1.5 \%$ suggested by the consultation would be very expensive and would require a very lengthy adjustment process. Indeed, cash-terms floors of $-3 \%$ or smaller would require at least $£ 1.6$ billion in additional funding and a transitional period of at least a decade.

In order to make these floors less expensive, the government could also implement a ceiling on annual increases in per-pupil funding and use the savings to cross-subsidise the floor. This might also be appealing if one 
believes that large sudden increases in funding would not be spent efficiently by schools. Imposing a ceiling would have the effect of staging any large gains over time. The final column of Table 5.1 illustrates the net cost of imposing each floor when a ceiling of $10 \%$ on annual cash-terms increases in funding per pupil is also imposed. This significantly reduces the cumulative total additional spending required. For example, if one chose to implement a floor of $-5 \%$ alongside a ceiling of $10 \%$ per year, the cumulative cost would fall from $£ 810$ million to $£ 380$ million in cash terms. The annual additional cost would fall to $£ 60$ million a year.

Nevertheless, it is important to remember that such transitional mechanisms would not stop individual schools from losing large amounts; the losses would simply be drawn out over a number of years. Furthermore, repeated cash-terms cuts in per-pupil funding of 5\% per year would still present a significant challenge for some schools.

\subsection{Conclusion}

Given the amount of turbulence that a national funding formula could create for school finances, it is important to consider the potential for smoothing the transition to the formula. Taking the 'Low Disruption' option with the combined ACA methodology, we find that it is possible to complete the transition within six years (i.e. by 2020) at an additional cost of $€ 380$ million ( $€ 60$ million a year).

However, this would not be painless for schools: some of them may incur repeated annual cash-terms funding losses of up to $5 \%$, and it remains to be seen whether sustained reductions of this magnitude are politically feasible. Given that a national funding formula creates winners and losers, the current environment (characterised by falling real-terms budgets) is sure to compound the challenges of implementing such a reform.

On the other hand, the risks of moving to a national funding formula should be weighed against the 'pain of the status quo': the complexities in the current system mean that schools' funding levels are not transparently related to their circumstances and are not responsive to immediate changes in needs. The crucial question for the government is whether the advantages of a national formula, such as greater simplicity, transparency and responsiveness of funding, are worth more than the costs that the adjustment process would entail. 


\section{Conclusions}

This Briefing Note has described in detail the mechanics and key features of the current school funding system. It has also considered the main design issues for moving to a national funding formula. Finally, it has demonstrated empirically the implications of implementing such a reform for school finances and pointed out the inevitable challenges involved.

While the level of funding that schools receive has increased in recent years, it exhibits very wide variation. To a large extent, this is because schools differ in their characteristics: those with a larger proportion of disadvantaged or high-needs pupils tend to be funded more generously. However, there is still some variation in funding levels across schools with very similar characteristics. School finances also depend on historical factors, such as the funding received in previous years, meaning that their funding adjusts slowly to changes in need. An explicit, transparent formula would depart from this, ensuring that funding levels respond immediately to changes in need.

The first key message from the empirical analysis of the implications of a national funding formula is that the specific monetary amounts involved must be chosen extremely carefully. Any formula that combines a ratio of secondary to primary funding of 1.27 with a $£ 95,000$ lump sum for primary schools (our interpretation of the government's proposals in the consultation) leads, on balance, to gains among primary schools but losses among secondary schools. To alleviate this, the funding ratio should be more heavily geared towards secondary school pupils. In our analysis, we use a funding ratio of 1.45 , which appears to minimise the redistribution from secondary to primary schools.

It is important to recognise as well that current levels of deprivation funding are also geared more strongly towards secondary schools. A formula that aimed to minimise disruption would need to implement a higher pupil premium at secondary schools than at primary schools. In total, we calculate that a pupil premium would need to be worth about $£ 4,400$ at primary schools and $£ 5,400$ at secondary schools in order to maintain the current levels of progressivity in the school funding system after the pupil premium is fully implemented.

Changes in funding will be concentrated in particular local authorities, with average gains and losses being more than $10 \%$ in some local authorities. In some cases, the changes amongst primary and secondary schools are offsetting, simply reflecting greater harmonisation across local authorities in the ratio of secondary to primary school funding. In other cases, both primary and secondary schools are expected to see large changes in funding. If one believes that a single national funding formula 
represents an appropriate system of school funding, then such local authorities would be deemed to be currently over- or under-funded. Alternatively, one might believe that some local authorities have higher or lower levels of educational need than those implied by the factors upon which a national formula might be based.

However, whatever formula is chosen, it will lead to a large number of winners and losers relative to existing policy, unless local authorities have complete discretion to set schools' allocations. This is an inevitable consequence of replacing the current system, where funding levels can be based on myriad historical and local factors, by a streamlined version where funding is more transparent and consistent across the country.

Given this, we consider the potential for staging the process of transition to a national funding formula. For the example formula used in this Briefing Note, it is possible to complete the transition at a relatively small additional cost to the government. However, the transition period could be long and entail significant, sustained annual losses for many schools - for example, losses of more than $5 \%$ per year. A key question that remains is whether sustained reductions of this magnitude are politically feasible.

Given that a national funding formula will create winners and losers, the current environment, characterised by falling real-terms budgets, is sure to compound the challenges of implementing such a reform. Ultimately, the likely future pain of this reform must be weighed against the pain of the status quo, with the system becoming less transparent and less related to educational need over time. The crucial question for the government is whether the advantages of a national formula, such as greater simplicity, transparency and responsiveness of funding, are worth more than the costs that the adjustment process would entail. However, the fact that there will be winners and losers is not an argument in itself against reform. If one believes that a national funding formula represents the most desirable school funding system, then the numbers of winners and losers just show how far we are from this system. If one considers a national funding formula to be right in principle, then failing to implement substantial reform to school funding would lead to a further drift away from the desirable system and a greater cost of implementing reform towards it in future. 


\section{APPENDIX}

Table A.1. Total funding for primary schools, 2010-11 (2010-11 prices)

\begin{tabular}{l|cc}
\hline & $\begin{array}{c}\text { Fair-funding } \\
\text { formula }\end{array}$ & All funding \\
\hline Base per-pupil amount & $2,292 * * *$ & $2,423 * * *$ \\
Extra amount per FSM pupil & $1,498 * * *$ & $2,011 * * *$ \\
Extra amount per EAL pupil & $213.6 * * *$ & $470.0 * * *$ \\
Extra amount per SEN pupil with statement & $9,961 * * *$ & $9,996 * * *$ \\
Extra amount per SEN pupil without statement & $340.0 * * *$ & $441.7 * * *$ \\
Extra amount per boarder & $-69,462 * * *$ & $-97,642 * * *$ \\
Extra amount per nursery pupil & $1,688 * * *$ & $1,853 * * *$ \\
Extra amount for being a VA/VC school & $-11,287 * * *$ & $-10,005 * * *$ \\
Extra amount for being a foundation school & $-13,905 * * *$ & $-14,743 * *$ \\
Constant & $112,185 * * *$ & $140,711 * * *$ \\
& & \\
Number of observations & 16,721 & 16,721 \\
Number of local authorities & 150 & 150 \\
\hline
\end{tabular}

Notes: Figures are coefficients from a least-squares regression of school funding levels on selected school characteristics. Asterisks denote statistical significance: $*=10 \%$ level; $* *=5 \%$ level; $* * *=1 \%$ level.

EAL - English as an additional language; FSM - free school meals; SEN - special educational needs; VA - voluntary aided; VC - voluntary controlled.

Table A.2. Total funding for secondary schools, 2010-11 (2010-11 prices)

\begin{tabular}{l|cc}
\hline & $\begin{array}{c}\text { Fair-funding } \\
\text { formula }\end{array}$ & All funding \\
\hline Base per-pupil amount & $3,320 * * *$ & $3,565 * * *$ \\
Extra amount per FSM pupil & $2,264 * * *$ & $3,418 * * *$ \\
Extra amount per EAL pupil & -17.93 & 88.76 \\
Extra amount per SEN pupil with statement & $8,737 * * *$ & $9,401 * * *$ \\
Extra amount per SEN pupil without statement & $286.1 * * *$ & $405.9 * * *$ \\
Extra amount per boarder & $297.5 * * *$ & $512.9 * * *$ \\
Extra amount for being a VA/VC school & $-69,509 * * *$ & $-68,445 * * *$ \\
Extra amount for being a foundation school & $-71,127 * * *$ & $-73,393 * * *$ \\
Extra amount per sixth-form pupil & -35.81 & $341.4 * * *$ \\
Extra amount for having a sixth form & $68,633 * *$ & 40,299 \\
Constant & $165,239 * * *$ & $286,783 * * *$ \\
& & \\
Number of observations & 3,055 & 3,055 \\
Number of local authorities & 150 & 150 \\
\hline
\end{tabular}

Notes: Figures are coefficients from a least-squares regression of school funding levels on selected school characteristics. Asterisks denote statistical significance: $*=10 \%$ level; $* *=5 \%$ level; $* * *=1 \%$ level.

EAL - English as an additional language; FSM - free school meals; SEN - special educational needs; VA - voluntary aided; VC - voluntary controlled. 
Table A.3. Responsiveness of total funding to changes over time in pupil characteristics: primary schools, 2010-11 (2010-11 prices)

\begin{tabular}{l|c}
\hline & All funding \\
\hline Base per-pupil amount & $2,183 * * *$ \\
Extra amount per FSM pupil & $971.9 * * *$ \\
Extra amount per EAL pupil & $1,398 * *$ \\
Extra amount per SEN pupil with statement & $3,804 * * *$ \\
Extra amount per SEN pupil without statement & $209.8 * *$ \\
Extra amount per boarder & $24,692 * * *$ \\
Extra amount per nursery pupil & $-1,546 * * *$ \\
Constant & $-2,181$ \\
Number of observations & 16,631 \\
Number of local authorities & 150 \\
\hline
\end{tabular}

Notes: Figures are coefficients from a least-squares regression of the annual change in school funding levels on the annual change in selected school characteristics. Asterisks denote statistical significance: * $=10 \%$ level; ** $=5 \%$ level; $\because * *=1 \%$ level. EAL - English as an additional language; FSM - free school meals; SEN - special educational needs.

Table A.4. Responsiveness of total funding to changes over time in pupil characteristics: secondary schools, 2010-11 (2010-11 prices)

\begin{tabular}{l|c}
\hline & All funding \\
\hline Base per-pupil amount & $1,662 * * *$ \\
Extra amount per FSM pupil & $2,084 * * *$ \\
Extra amount per EAL pupil & $91.60 * *$ \\
Extra amount per SEN pupil with statement & $8,667 * * *$ \\
Extra amount per SEN pupil without statement & $292.7 * * *$ \\
Extra amount per boarder & -159.7 \\
Extra amount per sixth-form pupil & $0.0324 * * *$ \\
Constant & $-39,198 * * *$ \\
& \\
Number of observations & 3,042 \\
Number of local authorities & 150 \\
\hline Notes: Figures are coefficients from a least-squares regression of the annual change in school funding levels on the \\
annual change in selected school characteristics. Asterisks denote statistical significance: * $=10 \%$ level; ** $=5 \%$ level; \\
$* * *=1 \%$ level. EAL - English as an additional language; FSM - free school meals; SEN - special educational needs.
\end{tabular}


Table A.5. Average percentage changes by local authority under 'Low Disruption' option and different assumptions for the Area Cost Adjustment, relative to expected funding per pupil in 2014-15 under existing policy

\begin{tabular}{|c|c|c|c|c|c|c|}
\hline \multirow[b]{2}{*}{ Local authority } & \multicolumn{2}{|c|}{ No change in ACA } & \multicolumn{2}{|c|}{ Combined approach } & \multicolumn{2}{|c|}{ Updated GLM approach } \\
\hline & Primary & Secondary & Primary & Secondary & Primary & Secondary \\
\hline Inner London & -3.0 & 1.4 & -3.7 & 1.3 & -1.1 & 3.3 \\
\hline Camden & 0.6 & -2.5 & -2.2 & -5.3 & 2.8 & -0.3 \\
\hline Hackney & -2.9 & 0.2 & -5.5 & -2.6 & -0.8 & 2.4 \\
\hline Hammersmith and Fulham & 3.5 & 7.2 & 0.6 & 4.3 & 5.7 & 9.6 \\
\hline Haringey & -9.7 & -7.0 & -3.1 & 0.0 & -8.7 & -5.9 \\
\hline Islington & 9.9 & 10.5 & 6.9 & 7.4 & 12.2 & 12.9 \\
\hline Kensington and Chelsea & -3.3 & -4.8 & -5.9 & -7.4 & -1.2 & -2.8 \\
\hline Lambeth & -5.5 & -1.7 & -8.1 & -4.4 & -3.4 & 0.4 \\
\hline Lewisham & 1.1 & 4.6 & -1.5 & 1.8 & 3.3 & 6.8 \\
\hline Newham & -13.6 & -1.6 & -7.4 & 5.8 & -12.7 & -0.5 \\
\hline Southwark & -9.5 & -7.9 & -12.1 & -10.5 & -7.5 & -5.8 \\
\hline Tower Hamlets & -1.9 & 6.9 & -4.6 & 4.0 & 0.2 & 9.2 \\
\hline Wandsworth & 2.6 & 8.5 & -0.2 & 5.5 & 4.7 & 10.7 \\
\hline Westminster & 11.9 & 5.9 & 9.1 & 3.1 & 14.1 & 8.1 \\
\hline Outer London & -0.3 & -0.3 & 1.0 & 1.0 & 0.9 & 0.9 \\
\hline Barking and Dagenham & 1.9 & -0.5 & 9.0 & 6.8 & 3.0 & 0.6 \\
\hline Barnet & -2.9 & -1.6 & -4.2 & -2.8 & -1.8 & -0.6 \\
\hline Bexley & 3.8 & -4.2 & 6.2 & $\begin{array}{l}-1.7 \\
\end{array}$ & 4.9 & -3.1 \\
\hline Brent & -5.7 & -6.4 & -2.7 & -3.2 & -4.7 & -5.4 \\
\hline Bromley & 11.9 & 3.3 & 14.6 & 6.0 & 13.1 & 4.5 \\
\hline Croydon & -2.9 & -5.3 & -0.6 & -2.8 & -1.8 & -4.1 \\
\hline Ealing & -8.6 & $\begin{array}{l}-1.7 \\
\end{array}$ & -5.5 & 1.6 & -7.5 & -0.6 \\
\hline Enfield & -6.6 & -6.5 & -4.3 & -4.1 & -5.5 & -5.3 \\
\hline Greenwich & 10.8 & 6.2 & 7.9 & 3.4 & 13.1 & 8.4 \\
\hline Harrow & 2.3 & -9.8 & 1.1 & -11.0 & 3.4 & -8.9 \\
\hline Havering & -2.1 & -7.4 & 0.3 & -5.0 & -0.9 & -6.3 \\
\hline Hillingdon & -2.9 & 4.0 & -4.2 & 2.7 & -1.8 & 5.1 \\
\hline Hounslow & 6.0 & 5.8 & 4.5 & 4.5 & 7.1 & 6.9 \\
\hline Kingston upon Thames & -4.0 & 0.8 & -5.3 & -0.5 & -3.0 & 1.9 \\
\hline Merton & -2.9 & 12.2 & 0.2 & 15.8 & -1.8 & 13.3 \\
\hline Redbridge & 3.7 & 6.6 & 6.1 & 9.1 & 4.8 & 7.7 \\
\hline Richmond upon Thames & 0.3 & -2.7 & -1.0 & -4.2 & 1.4 & -1.4 \\
\hline Sutton & 5.0 & 10.1 & 3.6 & 8.8 & 6.2 & 11.3 \\
\hline Waltham Forest & -6.9 & -4.5 & -4.6 & -2.2 & -5.8 & -3.5 \\
\hline East Midlands & 3.8 & 1.7 & 4.6 & 2.6 & 3.3 & 1.1 \\
\hline Derby & -1.3 & 1.1 & -0.4 & 2.2 & -1.9 & 0.3 \\
\hline Derbyshire & 7.7 & 9.1 & 8.7 & 10.2 & 7.0 & 8.3 \\
\hline Leicester & -1.9 & 1.7 & -1.0 & 2.6 & -2.0 & 1.5 \\
\hline Leicestershire & 1.6 & -0.9 & 2.4 & 0.0 & 1.5 & -1.1 \\
\hline Lincolnshire & 6.1 & -1.4 & 7.1 & -0.3 & 5.4 & -2.1 \\
\hline Northamptonshire & 9.3 & 3.5 & 9.1 & 3.3 & 8.7 & 2.7 \\
\hline Nottingham & 2.2 & -1.2 & 3.2 & 0.0 & 1.7 & $\begin{array}{l}-1.7 \\
\end{array}$ \\
\hline Nottinghamshire & 0.0 & -1.3 & 1.0 & -0.1 & -0.5 & -1.8 \\
\hline Rutland & -1.7 & -0.7 & -1.0 & 0.1 & -1.7 & -0.9 \\
\hline East of England & 3.9 & 0.3 & 2.8 & -0.6 & 3.9 & 0.1 \\
\hline Bedford Borough & 2.4 & 2.6 & -0.2 & 0.1 & 1.5 & 1.6 \\
\hline Cambridgeshire & 7.3 & 7.9 & 5.4 & 6.2 & 7.7 & 8.2 \\
\hline Central Bedfordshire & -0.5 & 2.4 & -3.1 & -0.1 & -1.3 & 1.4 \\
\hline Essex & -0.6 & -5.4 & -1.0 & -5.7 & -0.5 & -5.4 \\
\hline Hertfordshire & 10.5 & 0.3 & 7.5 & -2.6 & 11.2 & 0.9 \\
\hline Luton & -9.1 & -5.6 & -11.4 & -7.9 & -10.0 & -6.5 \\
\hline Norfolk & 7.3 & 4.9 & 8.2 & 5.9 & 6.6 & 4.2 \\
\hline Peterborough & 3.8 & -0.5 & 2.1 & -2.1 & 4.2 & -0.3 \\
\hline Southend-on-Sea & 2.7 & 0.4 & 3.2 & 1.0 & 2.7 & 0.4 \\
\hline Suffolk & 1.4 & -0.7 & 2.3 & 0.4 & 0.8 & $\begin{array}{l}-1.4 \\
\end{array}$ \\
\hline
\end{tabular}




\begin{tabular}{|c|c|c|c|c|c|c|}
\hline \multirow[b]{2}{*}{ Local authority } & \multicolumn{2}{|c|}{ No change in ACA } & \multicolumn{2}{|c|}{ Combined approach } & \multicolumn{2}{|c|}{ Updated GLM approach } \\
\hline & Primary & Secondary & Primary & Secondary & Primary & Secondary \\
\hline Thurrock & 2.4 & 4.3 & 0.4 & 2.2 & 2.5 & 4.3 \\
\hline North East & -2.7 & -4.5 & -1.8 & -3.5 & -3.4 & -5.2 \\
\hline Darlington & 8.7 & -1.8 & 9.8 & -0.7 & 8.0 & -2.5 \\
\hline Durham & -2.3 & -7.0 & -1.4 & -6.0 & -3.0 & -7.7 \\
\hline Gateshead & -2.0 & -8.5 & -1.1 & -7.5 & -2.7 & -9.3 \\
\hline Hartlepool & 0.3 & -2.3 & 1.2 & -1.2 & -0.4 & -3.1 \\
\hline Middlesbrough & -4.8 & -8.7 & -3.9 & -7.9 & -5.4 & -9.2 \\
\hline Newcastle upon Tyne & -4.3 & -9.9 & -3.3 & -8.9 & -4.9 & -10.6 \\
\hline North Tyneside & -2.5 & -6.1 & -1.5 & -5.1 & -3.1 & -6.8 \\
\hline Northumberland & -2.9 & 4.0 & -2.0 & 5.1 & -3.5 & 3.2 \\
\hline Redcar and Cleveland & -4.3 & -1.4 & -3.4 & -0.3 & -5.0 & -2.1 \\
\hline South Tyneside & -2.7 & -4.8 & -1.7 & -3.8 & -3.3 & -5.6 \\
\hline Stockton-on-Tees & -1.3 & -5.4 & -0.4 & -4.5 & -2.0 & -6.0 \\
\hline Sunderland & -7.3 & -5.8 & -6.3 & -4.8 & -7.9 & -6.5 \\
\hline North West & -0.6 & -2.1 & -0.2 & -1.6 & -1.0 & -2.6 \\
\hline Blackburn with Darwen & -2.8 & -6.8 & -1.9 & -5.8 & -3.5 & -7.5 \\
\hline Blackpool & 2.9 & 1.5 & 4.0 & 2.6 & 2.1 & 0.7 \\
\hline Bolton & 5.7 & -3.7 & 5.8 & -3.6 & 5.8 & -3.6 \\
\hline Bury & -3.2 & 1.8 & -3.2 & 2.0 & -3.1 & 1.9 \\
\hline Cheshire East & 2.3 & 0.8 & 1.9 & 0.5 & 1.0 & -0.7 \\
\hline Cheshire West and Chester & 1.3 & 6.8 & 1.0 & 6.5 & 0.0 & 5.2 \\
\hline Cumbria & 3.0 & 6.4 & 3.9 & 7.5 & 2.4 & 5.6 \\
\hline Halton & 2.0 & -7.1 & 1.6 & -7.7 & 0.6 & -8.1 \\
\hline Knowsley & 5.5 & -1.7 & 6.6 & -0.4 & 5.3 & -2.0 \\
\hline Lancashire & -0.4 & -2.7 & 0.6 & -1.6 & -1.0 & -3.4 \\
\hline Liverpool & -7.1 & -11.5 & -6.1 & -10.4 & -7.4 & -11.8 \\
\hline Manchester & -6.4 & -3.4 & -6.4 & -3.3 & -6.3 & -3.3 \\
\hline Oldham & 2.2 & -6.6 & 2.2 & -6.7 & 2.3 & -6.5 \\
\hline Rochdale & -3.0 & -6.0 & -3.0 & -6.0 & -2.9 & -5.9 \\
\hline Salford & 3.6 & 0.1 & 3.6 & 0.2 & 3.8 & 0.1 \\
\hline Sefton & -6.5 & -6.3 & -5.5 & -5.1 & -6.7 & -6.6 \\
\hline St. Helens & -2.4 & -7.4 & -1.3 & -6.4 & -2.6 & -7.6 \\
\hline Stockport & 4.7 & 6.0 & 4.7 & 6.2 & 4.8 & 6.1 \\
\hline Tameside & -2.4 & -0.4 & -2.4 & -0.5 & -2.3 & -0.2 \\
\hline Trafford & -5.0 & -6.6 & -5.0 & -6.6 & -4.9 & -6.5 \\
\hline Warrington & 1.8 & 5.8 & 1.5 & 5.6 & 0.5 & 4.4 \\
\hline Wigan & -7.9 & -8.1 & -7.9 & -8.0 & -7.8 & -8.1 \\
\hline Wirral & 4.9 & -0.4 & 6.1 & 0.8 & 4.6 & -0.7 \\
\hline South East & 3.4 & 3.3 & 1.3 & 1.2 & 3.8 & 3.6 \\
\hline Bracknell Forest & 10.2 & 7.4 & 5.6 & 2.9 & 12.1 & 9.2 \\
\hline Brighton and Hove & -0.5 & -5.4 & -0.4 & -5.4 & -1.3 & -6.2 \\
\hline Buckinghamshire & 3.8 & 15.8 & 0.0 & 11.7 & 5.0 & 17.1 \\
\hline East Sussex & 4.1 & 5.3 & 4.2 & 5.5 & 3.3 & 4.4 \\
\hline Hampshire & 5.2 & 7.5 & 3.5 & 5.9 & 5.3 & 7.5 \\
\hline Isle of Wight & -10.2 & 7.4 & -11.8 & 5.7 & -10.0 & 7.4 \\
\hline Kent & 1.0 & -5.7 & 1.1 & -5.6 & 0.7 & -6.0 \\
\hline Medway & 2.3 & -3.6 & 2.7 & -3.3 & 1.9 & -3.9 \\
\hline Milton Keynes & 2.5 & -0.4 & -1.4 & -4.1 & 3.7 & 0.7 \\
\hline Oxfordshire & 5.0 & 1.8 & 1.6 & -1.4 & 5.5 & 2.2 \\
\hline Portsmouth & 4.6 & 6.3 & 2.9 & 4.7 & 4.6 & 6.3 \\
\hline Reading & 4.5 & 7.4 & -2.1 & 0.9 & 5.9 & 8.7 \\
\hline Slough & 4.2 & -3.6 & 0.0 & -7.6 & 5.9 & -2.0 \\
\hline Southampton & 8.1 & 0.7 & 6.4 & -0.8 & 8.1 & 0.6 \\
\hline Surrey & 8.0 & 9.2 & 3.3 & 4.6 & 9.8 & 11.0 \\
\hline West Berkshire & 7.8 & 4.7 & 1.1 & -1.8 & 9.3 & 6.0 \\
\hline West Sussex & -4.4 & -0.1 & -4.5 & -0.1 & -4.8 & -0.6 \\
\hline Windsor and Maidenhead & 7.3 & 4.3 & 2.7 & -0.1 & 9.1 & 6.0 \\
\hline Wokingham & 2.3 & 6.0 & -4.2 & -0.7 & 3.7 & 7.3 \\
\hline
\end{tabular}




\begin{tabular}{|c|c|c|c|c|c|c|}
\hline \multirow[b]{2}{*}{ Local authority } & \multicolumn{2}{|c|}{ No change in ACA } & \multicolumn{2}{|c|}{ Combined approach } & \multicolumn{2}{|c|}{ Updated GLM approach } \\
\hline & Primary & Secondary & Primary & Secondary & Primary & Secondary \\
\hline South West & 4.7 & -0.5 & 4.8 & -0.2 & 4.3 & -1.0 \\
\hline Bath and North East Somerset & 7.4 & 0.2 & 5.8 & -1.2 & 7.1 & -0.1 \\
\hline Bournemouth & 1.2 & 0.1 & 2.2 & 1.0 & 0.4 & -0.6 \\
\hline Bristol City of & 2.8 & -4.0 & 1.4 & -5.3 & 2.5 & -4.4 \\
\hline Cornwall & 0.6 & -4.5 & 1.5 & -3.5 & -0.1 & -5.2 \\
\hline Devon & 5.0 & -0.2 & 6.0 & 0.9 & 4.3 & -0.9 \\
\hline Dorset & 4.2 & 0.7 & 5.2 & 1.8 & 3.5 & 0.0 \\
\hline Gloucestershire & 7.4 & -0.1 & 7.1 & -0.3 & 6.8 & -0.8 \\
\hline North Somerset & 6.1 & 6.3 & 4.7 & 4.9 & 5.9 & 6.0 \\
\hline Plymouth & 6.8 & -2.8 & 7.8 & -1.9 & 6.1 & -3.5 \\
\hline Poole & 5.1 & -6.5 & 6.2 & -5.5 & 4.3 & -7.2 \\
\hline Somerset & 3.2 & 1.9 & 4.1 & 3.0 & 2.5 & 1.2 \\
\hline South Gloucestershire & 12.7 & 4.9 & 11.2 & 3.6 & 12.5 & 4.6 \\
\hline Swindon & 3.9 & 0.9 & 3.5 & 0.6 & 4.3 & 1.3 \\
\hline Torbay & 4.0 & -2.6 & 5.1 & -1.5 & 3.3 & -3.3 \\
\hline Wiltshire & 2.6 & -2.8 & 2.2 & -3.0 & 3.1 & -2.4 \\
\hline West Midlands & -2.7 & -1.5 & -2.4 & -1.1 & -3.4 & -2.3 \\
\hline Birmingham & -8.9 & -4.1 & -9.0 & -4.2 & -9.7 & -5.0 \\
\hline Coventry & -6.8 & -8.1 & -6.9 & -8.2 & -7.6 & -9.0 \\
\hline Dudley & -5.9 & -1.8 & -6.1 & -1.9 & -6.8 & -2.8 \\
\hline Herefordshire & -3.3 & -7.4 & -2.4 & -6.3 & -3.9 & -8.1 \\
\hline Sandwell & -6.5 & 3.2 & -6.6 & 3.2 & -7.3 & 2.3 \\
\hline Shropshire & 2.1 & -5.8 & 3.0 & -4.8 & 1.4 & -6.6 \\
\hline Solihull & 0.8 & 3.2 & 0.6 & 3.1 & 0.0 & 2.2 \\
\hline Staffordshire & 0.6 & -1.5 & 1.6 & -0.4 & -0.1 & -2.2 \\
\hline Stoke-on-Trent & 3.6 & 0.3 & 4.7 & 1.3 & 2.9 & -0.3 \\
\hline Telford and Wrekin & 5.0 & -0.6 & 6.0 & 0.5 & 4.3 & -1.3 \\
\hline Walsall & -8.0 & -2.9 & -8.1 & -3.0 & -8.8 & -3.9 \\
\hline Warwickshire & 8.5 & 9.2 & 8.2 & 9.1 & 8.2 & 8.9 \\
\hline Wolverhampton & -8.0 & -12.4 & -8.2 & -12.5 & -8.9 & -13.2 \\
\hline Worcestershire & 1.4 & 0.9 & 2.4 & 1.9 & 0.7 & 0.1 \\
\hline Yorkshire and Humber & -3.0 & -3.8 & -2.2 & -2.9 & -3.4 & -4.3 \\
\hline Barnsley & -9.0 & -3.5 & -8.1 & -2.4 & -9.6 & -4.2 \\
\hline Bradford & -12.9 & -4.7 & -12.2 & -4.0 & -13.0 & -5.0 \\
\hline Calderdale & -1.9 & -0.1 & -1.2 & 0.6 & -2.1 & -0.3 \\
\hline Doncaster & 1.4 & -6.1 & 2.4 & -5.1 & 0.7 & -6.9 \\
\hline East Riding of Yorkshire & 0.9 & -2.0 & 1.8 & -0.9 & 0.2 & -2.8 \\
\hline Kingston upon Hull City of & 1.5 & 1.1 & 2.5 & 2.2 & 0.8 & 0.3 \\
\hline Kirklees & -6.0 & -0.2 & -5.4 & 0.6 & -6.2 & -0.4 \\
\hline Leeds & -1.4 & -5.4 & -0.8 & -4.7 & -1.6 & -5.7 \\
\hline North East Lincolnshire & -7.4 & -7.9 & -6.5 & -7.2 & -8.0 & -8.5 \\
\hline North Lincolnshire & 4.8 & -1.4 & 5.8 & -0.3 & 4.1 & -2.2 \\
\hline North Yorkshire & -0.2 & -5.9 & 0.7 & -4.9 & -0.8 & -6.7 \\
\hline Rotherham & -4.8 & -12.7 & -3.8 & -11.8 & -5.5 & -13.4 \\
\hline Sheffield & 1.5 & -0.2 & 2.5 & 0.9 & 0.9 & -0.9 \\
\hline Wakefield & -3.1 & -4.1 & -2.6 & -3.3 & -3.3 & -4.3 \\
\hline York & -1.6 & -0.5 & -0.6 & 0.6 & -2.2 & -1.2 \\
\hline
\end{tabular}

